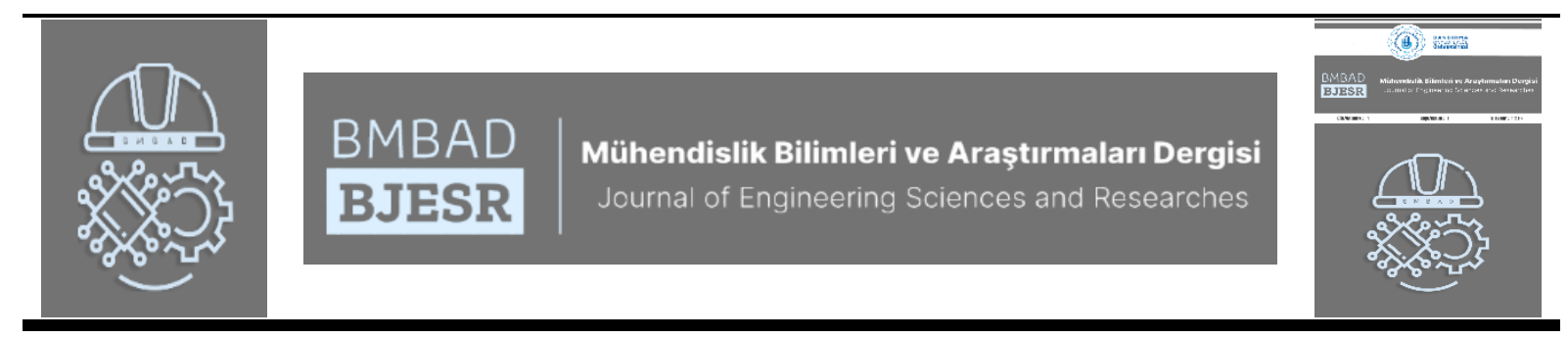

\title{
Düşük-Işılkı Renkli Görüntülerin İyileştirilmesinde Kullanılan Retineks Algoritmalarının Karşılaştırmalı Analizi
}

\section{Comparative Analysis of Retinex Algorithms used in Low-Light Color Image Enhancement}

${ }^{1}$ Ferzan KATIRCIOĞLU

${ }^{I}$ Düzce Üniversitesi, Düzce Meslek Yüksekokulu, Elektronik ve Otomasyon Bölümü, Düzce, Türkiye

${ }^{1}$ ferzankatircioglu@düzce.edu.tr

Araştırma Makalesi/Research Article

A R T I C L E I N F O
Article history
Received : 21 June 2021
Accepted : 14 October 2021

\section{Keywords:}

Low-Light Color Image Enhancement, Retinex Algorithm, Comparison metrics.

\section{A B S T R A C T}

In color image applications taken under insufficient or uneven light, undesirable situations such as low brightness, poor contrast and sudden changes in light occur. The Retinex theory, which is widely used to low-light color image enhancement, was generally developed to analyze local image derivatives and decompose them into illumination and reflectance components. This paper presents a comparative analysis of state-of-the-art image enhancement algorithms based on Retinex-based algorithms. For this, ten highly preferred Retinex-based methods, which have been used to lowlight color image enhancement, have been taken. In addition, five commonly used benchmark measurement metrics were analyzed and used as performance comparison. Comparison results are given visually and numerically. This comparative analysis study aims to assist researchers to develop new efficient algorithms in the field of Retinex-based image enhancement.

\section{Anahtar Kelimeler:}

Düşük Işıklı Renkli Görüntü Iyileştirme,

Retineks Algoritmas1, Karşılaştırma metrikleri.
(C) 2021 Bandirma Onyedi Eylul University, Faculty of Engineering and Natural Science. Published by Dergi Park. All rights reserved.

\section{Ö Z E T}

Yetersiz veya düzgün olmayan 1şık altında alınan renkli görüntü uygulamalarında, düşük parlaklık, zayıf kontrast ve 1şıkta ani değişiklik gibi istenmeyen durumlar meydana gelmektedir. Düşük 1şıklı renkli görüntülerini iyileştirilmesi için yaygın kullanılan Retineks teorisi, genel olarak yerel görüntü türevlerini analiz ederek, aydınlatma ve yansıtma bileşenlerine ayırmak için geliştirilmiştir. $\mathrm{Bu}$ çalışma, Retineks tabanlı algoritmalara dayanan son teknoloji görüntü geliştirme algoritmalarının karşılaştırmalı bir analizini sunmaktadır. Bunun için günümüze kadar düşük 1şıklı renkli görüntülerin iyileştirilmesinde kullanılan ve çok tercih edilen on adet Retineks esaslı yöntem alınmıştır. Ayrıca beş adet yaygın kullanılan karşılaştırma ölçüm metrikleri de incelenmiş ve performans karşılaştırması olarak kullanılmıştır. Karşılaştırma sonuçları görsel ve sayısal olarak verilmiştir. $\mathrm{Bu}$ karşılaştırmalı analiz çalışması Retineks esaslı görüntü iyileştirme alanında yeni verimli algoritmalar geliştirmek için araştırmacılara yardımcı olmayı amaçlamaktadır. 


\section{GİRIŞ}

Renkli görüntü uygulamalarında sık sık görüntüler arzu edilmeyen hava koşulları ve parlaklık durumlarında elde edilmektedir. Yetersiz veya düzgün olmayan ışı altında alınan görüntülere, düşük parlaklık, zayıf kontrast, bulanıklaşmış yerel detaylar, zayıf renk kalitesi, ışıkta ani değişiklikler ve hatta çoğu zamanda çok fazla gürültü eşlik etmektedir.

Düşük 1şıklı görüntüleri iyileştirmenin sezgisel yollarından biri doğrudan aydınlatmanın yükseltilmesidir. Bu düşünce ile gerçekleştirilmiş çalışmalardan olan Histogram Equalization (HE) kontrast ve parlaklığı ayarlamak için kullanılan en temel yöntemlerdendir (1). HE, giriş görüntüsünün histogramının yoğunluk seviyelerini bütün bir aralık boyunca eşit olarak dağıtma özelliğine sahiptir (2). Ancak nispeten parlak alanlarda aşırı kontrast artışından dolayı doygunluk ve işlem sırasında bazı detay kaybolmaları meydana gelmektedir. Görüntünün ortalama parlaklık değerini koruyarak histogram eşitleme yönteminin uygulanması, HE'den önce ağırlaştırma ve eşikleme işlemi yapılarak farklı görüntüler için kullanışlı ve pürüzsüz görüntüler elde edilmesi amaçlanmıştır (3) (4). HE esaslı bu çalışmaların genelinde görüntünün doğasında yer alan gerçek aydınlatma nedenlerinden yararlanmak yerine, aşırı ve yetersiz geliştirme riskine sahip olarak kontrast artırmaya odaklanılması en büyük eleştiri nedenleridir.

Bazı araştırmacılar düşük ışıklı görüntülerin tersini aldıklarında puslu görüntülere benzediklerini fark ettiler. Buğulanmayı önleyici yöntemler (dehazing methods) uygulamaya sokularak başlanır ve iyileştirme sonucu olarak ise buğu önleme sonuçları tekrar tersine çevrilmektedir (5) (6). Zhang ve arkadaşlarının önerdikleri çalışmada, gürültüleri bastırmak için ortak iki taraflı (joint-bilateral) filtre iyileştirme işleminden sonra uygulanmıştır (6). Li ve arkadaşları ise farklı bölgeler için uyarlamalı gürültü giderici süper piksel uygulamasını kullanmışlardır (5). İyileştirme ve gürültü giderme işleminin sıralı yapılması gürültünün iyileştirme aşamasında büyüme ihtimalinden dolayı gürültü giderme işlemini zorlaştırmıştır. Ayrıca, dayandıkları temel model fiziksel açiklamadan yoksundur.

Birçok araştırmacı da bir görüntünün kontrast ve parlaklık iyileştirmesi için gamma düzeltme metodunu tercih etmişlerdir. Ancak gamma parametresinin seçimi manuel ve zaman alıcıdır. An adaptive gamma correction (AGC) metodunda görüntüden alınan istatiksel veriler ile uygun gamma değeri bulunmakta ve bu sayede kontrast iyileştirilmesi otomatik olarak gerçekleştirilmektedir (7). Bir diğer çalışmada, düşük 1şıklı görüntüleri iyileştirmek için aydınlık piksellerin olasılık dağılımını ve gamma düzeltme metodunu birlikte kullanan bir yöntem önerilmiştir. Adaptive gamma correction with weighting distribution (AGCWD) adını verdikleri yöntem, hesaplama karmaşıklığını azaltmak için her bir yapı arasındaki farkları geçici bilgi olarak kullanmaktadır (8). Gölge ve yüksek 1şık alanlarında düşük kontrast problemlerine çözüm aramak için gamma düzeltme algoritmasının genelleştirilmesi önerilmiştir. Generalized linear system (GLS)'nin çarpımı ile yapılan genelleme işlemi, Symmetric Logaritmic Image Processing (SLIP) modeli adında kullanılmıştır (9). Global ve yerel kontrast iyileşmesinde istenilen başarı sağlanmış, fakat ortalama parlaklık parametresi üzerinde durulmadığından görüntünün doğallığından uzaklaşılmıştır. Gama düzeltme algoritmalarının ana dezavantajı her bir pikseli komşuları ile olan bağlantısını düşünmeksizin bağımsız tek bir pikselmiş gibi işlem yapılmasıdır. Bunun sonucu olarak da, görüntü içerisindeki sahnelerde görsel tutarsızlık kendini göstermiştir.

Uzamsal bölge esaslı görüntü iyileştirme teknikleri arasında yerini almış olan retineks teorisinde görüntü, aydınlatma ve yansıtmanın bir ürünü gibi sunulmuştur. Genel olarak retineks esaslı algoritmalarda iyileştirilmiş görüntü, giriş görüntüsünden aydınlatma bileşeninin tahmini ve sonra yansıtma bileşeninin alınması ile elde edilmektedir. The single-scale retinex (SSR) ve multi-scale retinex (MSR) algoritmalar1 yerel Gaussian filtrelerini kullanarak aydınlatma ve yansıtma bileşenlerinin ayrılması sağlanmıştır (10) (11). Ancak bu algoritmalarda yapay hale etkisi ( görüntü içerisinde oluşan yapay 1şık halkaları veya 1şı çemberleri) ve renk bozulma problemleri ile karşı karşıya kalınmıştır. Aynı yıllarda gerçekleştirilen in multi-scale retinex with colour restoration (MSRCR) de görüntülerde iyi bir renk sunumu gerçekleştirebilmek için MSR tekniğine renk restorasyon fonksiyonu eklenmiştir (12). Michael ve arkadaşlarının 2011 de ki çalışmalarında Bregman döngüsü benimsenerek yansıtma bileşeninin ayrışmasını sağlayan toplam varyasyon modeli önermişlerdir. Yansıtma bileşeninin restore edilme işlemi logaritmik fonksiyonun yan etkisi nedeni ile aşırı yumuşatma ve ince detay kaybolmaları gerçekleşmiştir (13). Wang ve arkadaşlarının 2013 de yaptıkları çalışmada, görüntünün yerel varyasyonunu geliştiren ve yoğunluğun global eğilimini koruyan iyileştirme algoritması önerilmiştir. İlk önce orijinal görüntü bright-pass filtre kullanılarak aydınlatma ve yansıtma olacak şekilde ayrıştırılmıştır. Aydınlatma bileşeni bi-log transfer işlemi ile güncellenerek yansıtma ile tekrar sentezlenmiştir (14). Takip eden yıllar içerisinde 2015 de, doğrusal düzlem içerisinde eşzamanlı yansıtma ve aydınlatma tahmini yapabilen, logaritmik düzleme göre detayları daha iyi koruyan olasılık temelli bir yöntem önerilmiştir. Simultaneous reflectance and illumination estimation (SRIE) olarak adlandırılan bu yöntemde, basitleştirilmiş bir varsayıma dayanmasından dolayı aydınlatma değişim eğilimindedir. Farklı yönlerdeki farklı yüzeyler farklı aydınlatma ile karşı karşıya kalır ve bu da kenarlara yakın bölgelerin aydınlatmasının yanlış tahmin edilmesine neden olmaktadır (15).

Fu ve arkadaşlarının 2016 yılında önerdikleri Multi-scale Fusion Enhancing Method (MF) adındaki çalışmada, üç renk kanalından maksimum değeri alınarak füzyon işlemi için üç farklı giriş elde edilmiştir. Bulunan aydınlatma ilk giriş olarak, morfolojik kapama işlemi ile aydınlatmanın yeniden tasarımı gerçekleştirilmektedir. İkinci giriş, görüntünün karanlık bölgelerinin netleştirmek için arc tanjant dönüşümü global aydınlatma amaçlı olarak kullanılmıştır. Üçüncü ve son giriş olarak ise yerel kontrast ayarı yapmak için Contrast Local Adaptive 
Histogram Equalization (CLAHE) kullanılmıştır. Bu üç girişin hangi oranda kullanılacağını belirlemek için kromatik kontrast ağırlıkları kullanılmıştır. Son işlem olarak, elde edilen aydınlatma çıktısı yansıtma bileşeni ile tekrar birleştirilerek iyileştirilmiş görüntü elde edilmektedir (16). Guo ve arkadaşları 2017 yılında basit ama etkili düşük ışık iyileştirme algoritması önermişlerdir. Yansıtma ve aydınlatma bileşenlerini içeren bir görüntüyü ayrıştırmayı hedefleyen geleneksel Retinex metotlarından en belirgin farkı çözüm uzayını daraltmak ve hesaplama karmaşıklığını azaltmak için sadece aydınlatmayı tahmin etmeye çalışmasıdır (17). Ortak içsel dışsal öncelikli model (Joint Intrinsic-Extrinsic Prior Model, JieP) olarak adlandırılan ve 2017 de sunulan Retinex modelinde, doğrusal alan içinde aydınlatma ve yansıtma aynı anda ayrışabilen özelliktedir. Çalışmanın ilk bölümünde yerel varyasyon sapması adı verilen özellik ile içsel özellikler içinde yer alan yapının korunması amaçlanmıştır (18). Li ve arkadaşlarının 2018 de önerdikleri çalışmanın en önemli özelliği, eş zamanlı olarak yapıyı ortaya çıkartan yansıtma ve alternatif optimizasyon fonksiyonu kullanılarak gürültülerden arındırılmış aydınlatma tahminlerini yapmasıdır. Alternatif ayrıştırma adı verilen bu yöntemde gürültünün dağılımını tahmin etmek yerine giriş görüntüsünde gürültü haritası tahmini gerçekleştirilmiştir (19). Yöntem içerisinde aydınlatma bileşeninin pürüzsüz varsayılması, yansıtma haritasında gözlenebilir gürültülere yol açmıştır.

Ren ve arkadaşlarının sundukları çalışma son yıllarda yapılıış çalışma olup, düşük sıralı düzenlenmiş retineks modeli (Low-Rank Regularized Retinex Model, LR3M) adını almıştır. LR3M retineks modelinin en temel özelliği yansıtma haritasındaki gürültüyü bastırmak için retineks ayrıştırma işlemi içerisine öncelikli düşük sıralı mantığının yerleştirilmesidir. Önerilen metot parça bazlı düzleştirilmiş aydınlatma ve bastırılmış gürültülü yansıtma bileşenlerini sunmaktadır (20). Son olarak Xu ve arkadaşları üstel yerel türevler kullanılarak yapı ve doku haritalamaları üretilerek iyileştirme işlemini gerçekleştirmişlerdir. Bunun için ilk olarak esnek yapı ve doku tahmini için yerel türevlerin üstel versiyonu (Exponentiated Mean Local Variance EMLV) önerilmiştir (21). Yapı ve dokuya duyarlı Retineks (Structure and Texture Aware Retinex, STAR) adını verdikleri bu modelin çözümü, vektörize edilmiş en küçük kareler regresyona dönüştürülen alternatif optimizasyon algoritması ile gerçekleştirilmiştir.

$\mathrm{Bu}$ çalışmada doksanlı yıllardan günümüze kadar gelen düşük 1şıklı renkli görüntülerin iyileştirilmesinde kullanılan Retineks esaslı yöntemler incelenmiştir. Ayrıca bu yöntemlerin performans değerlendirilmesinde en çok tercih edilen karşılaştırma metrikleri de çalışmamızın kapsamı içerisinde yer almıştır. Retineks esaslı iyileştirme yöntemleri karşılaştırmalı olarak analizleri yapılmış, bu algoritmaların literatüre kazandırdıkları ve birbirlerini tamamlayan veya birbirleri ile çelişen argümanları ortaya konulmuştur. Bu konuda bilgi üretme amacının güden lisans ve yüksek lisans düzeyindeki öğrenciler için genel ve açıklayıcı makale formatı tercih edilmiştir. Bundan dolayı çalışmamızın ikinci bölümde, Retineks esaslı iyileştirme yöntemlerine yer verilirken 3. Bölümünde performans karşılaştırma metrikleri sunulmuştur. Dördüncü bölümde "Deneysel sonuçlar ve performans analizleri” başlığı altında görsel ve sayısal sonuçlara yer verilmiştir. Son bölümde ise kullanılan yöntemlerin önemleri vurgulanarak, ileride yapılabilecek çalışmalar için öneriler sunulmuştur.

\section{RETINEKS ESASLI GÖRÜNTÜ IYYILEȘTIRME ÇALIȘMALARI}

Retineks, bilimsel deneylere ve bilimsel analize dayalı, yaygın olarak kullanılan bir görüntü geliştirme yöntemidir. Edwin.H.Land tarafından 1971 de önerilmiştir. Retineks kelimesi retina ve korteks olan iki kelimenin sentezlenmesiyle oluşturulmuştur. Şekil 1. de bir görüntünün iki ayrı bileşenden oluşan aydınlatma ve yansıtma bileşenlerinin sembolik sunumu gerçekleştirilmiştir.

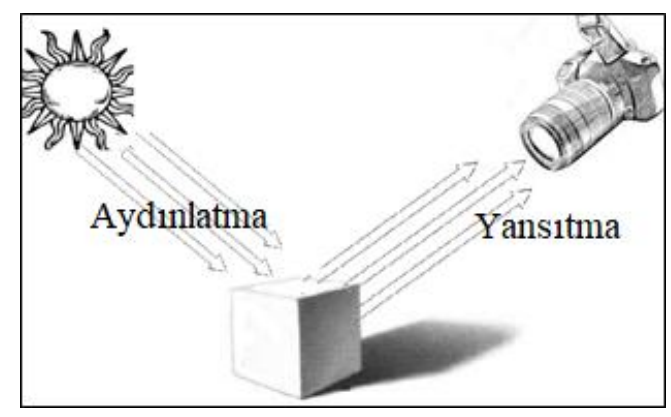

Şekil 1. Retineks yönteminin bileşenleri

Retineks teorisine göre, $I(x, y)$ görüntüsü aydınlatma görüntüsü $L(x, y)$ ve yansıyan görüntü $R(x, y)$ olmak üzere iki farklı görüntüye ayrıştırılabilir (22) (23).

$I(x, y)=L(x, y) R(x, y)$

Eşitlik (1) de ki $L(x, y)$ aydınlatmayı temsil ederken, $R(x, y)$ ise nesnenin karakteristik özelliğine göre yansıtma görüntüsüdür. 


\subsection{Tek Ölçekli Retineks (Single Scale Retinex SSR)}

İnsan gözünde görüntüyü oluşturmak için gelen ş̧ık yansıtıcı nesneye ışınlanır ve daha sonra bu nesneden yansımaktadır. Elde edilen görüntü aşağıdaki formül ile temsil edilmektedir (10).

$R_{i}(x, y)=\log I_{i}(x, y)-\log \left[F(x, y) * I_{i}(x, y)\right]$

Eşitlik (2) deki $R_{i}(x, y)$ retineks çıkışını, $I_{i}(x, y)$ i. spektral bant içindeki görüntü dağılımını, * evrişim işlemini ve $F(x, y)$ ise çevirme fonksiyonu olarak tanımlanmıştır. Çevirme fonksiyonu aşağıda Eşitlik (3) de sunulmuştur.

$F(x, y)=K e^{-r^{2} / c^{2}}$

Eşitlik (3) deki çevirme fonksiyonu olarak Gaussian fonksiyonu tercih edilmiş olup, $c$ çevirme uzay sabiti ve $\mathrm{K}$ ise Eşitlik (4) de verildiği gibi seçilmektedir (10).

$\iint F(x, y) d x d y=1$

\section{2. Çok Ölçekli Retineks (Multi Scale Retinex MSR)}

MSR çıkışı çeşitli farklı SSR çıkışlarının ağırlaştırılmış toplamı olarak tanımlanmaktadır.

$R_{M S R_{\mathrm{I}}}(x, y)=\sum_{n=1}^{N} w_{n}\left\{\log I_{i}(x, y)-\log \left[F(x, y) * I_{i}(x, y)\right]\right\}$

Eşitlik (5) de verilen MSR tekniğini SSR'den ayıran en önemli yanı Eşitlik (6) da daha basit formda sunulmuştur.

$R_{M S R_{\mathrm{i}}}=\sum_{n=1}^{N} w_{n} R_{n_{i}}$

Eşitlik (5) ve (6)'da ki $N$ ölçek sayısını, $R_{n_{\tilde{i}}} n$. ölçeğin $i$. kompenentinin yansıtma değeri ve $w_{n}$ ise $n$. ölçeğin ağrılık değerini temsil etmektedir.

SSR tekniğinin renk/açıklık yorumlanmasını veya dinamik aralık sıkıştırmasını yapabildiğini ancak her iki işlemi aynı anda yapamadığı görülmüştür. Bu problemi ortadan kaldıran çok ölçekli versiyonu kullanılmıştır (11).

\subsection{Renk Restorasyonu Çok Ölçekli Retineks (Multi Scale Retinex with Color Restoration MSRCR)}

Bölgesel veya küresel gri tonlar içeren görüntüler üzerinde retineks işlemi görüntünün genelinin grileşme meydana getirmektedir. Bu durum bazı durumlarda rengin hafiflemesi (desaturation) olacak şekilde, daha ciddi bir hal almaktadır. Görüntülerde iyi bir renk sunumu gerçekleştirebilmek için MSR tekniğine renk restorasyon fonksiyonu (color restoration function CRF) eklenmiştir (12).

$R_{M S R C R_{\mathrm{i}}}(x, y)=C_{i}(x, y) R_{M S R_{i}}(x, y)$

Eşit (7) de ki $C_{i}(x, y) i$. banttaki renk restorasyon fonksiyonunu temsil etmekte olup, açılımı Eşitlik (8) de yer verilmiştir.

$C_{i}(x, y)=f\left[I_{i}^{\prime}(x, y)\right]$

Eşitlik (8) içerisinde yer alan $I_{i}^{\prime}(x, y)$ görüntünün renklilik özelliğidir ve Eşitlik (9) da yer aldığı şekilde elde edilmektedir.

$I_{i}^{\prime}(x, y)=I_{i}(x, y) / \sum_{i=1}^{s} I_{i}(x, y)$

Eşitlik (9) da $S$, $i$. renk kanalının spektral kanal sayısı olup, renk uzayı RGB kullanıldığı için 3 alınmaktadır (12).

\subsection{Doğalık Korumalı İyileştirme Algoritması (Naturalness Preserved Enhancement Algorithm NPE)}

$\mathrm{Bu}$ çalışma içerisinde görüntünü yerel varyasyonu geliştiren ve aynı zamanda yoğunluğun global eğilimini koruyan doğallık koruma ile birlikte detayları iyileştiren bir çalışma önerilmiştir. Bundan dolayı, detay kısıtlaması olarak yansıtma [0], [1] aralı̆̆ında sınırlandırılması, ikinci olarak ise doğallık kısıtlaması olarak farklı yerel alanlar içinde bağıl aydınlatma düzeni büyük ölçüde değiştirilmemesi sağlanması amaçlanmıştır (14).

İlk önce orijinal görüntü bright-pass filtre kullanılarak aydınlatma ve yansıtma olacak şekilde ayrıştırılmıştır. Eşitlik (10) da yer alan bright-pass filtresi kullanılarak aydınlatmanın tahmini gerçekleştirilmiştir. 
$L_{r}(x, y)=\frac{1}{W(x, y)} \sum_{(i, j) \in \Omega}(Q(L(x, y), L(i, j)) \cdot U(L(i, j), L(x, y)) \cdot L(i, j))$

Eşitlik (10) da ki $L(x, y)$ değerleri için Eşitlik (11) de yer alan maksimum kanal yöntemi tercih edilmiştir. Ayrıca, $\Omega$ 15x15 büyüklüğünde bir yerel alanı, $U$ ise karşılaştırma yapan birim basamak fonksiyonudur, Eşitlik (12) de yer verilmiştir.

$$
\begin{aligned}
& L(x, y)=\max _{c \in[r, g, b]} I^{c}(x, y) \\
& U(a, b)=\left\{\begin{array}{cc}
1, f \text { or } & a \geq b \\
0, & \text { else }
\end{array}\right.
\end{aligned}
$$

Eşitlik (10) daki $Q$ işlemi parlak geçiren filtre özelliğine konu olan dörtlü komşuluk ilişkisini bulunduran frekans belirleyicidir. $W(x, y)$ ise normalleştirme faktörü olup piksel ağırlıklarının toplamının 1 olmasını sağlamaktadır. Eşitlik (13) de yer verilmiş̧tir.

$W(x, y)=\sum_{(i, j) \in \Omega}(Q(L(x, y), L(i, j)) \cdot U(L(i, j), L(x, y))$

Aydınlatmanın tahmini yapıldıktan sonra Eşitlik (14) de her bir renk kanalı için yansıtma görüntüsü elde edilmektedir.

$R^{c}(x, y)=I^{c}(x, y) / L_{r}(x, y)$

İkinci aşama olarak aydınlatma bi-log transfer kullanılarak işlenmiştir.

$$
L_{m}(x, y)=c f^{-1}\left[c L\left(L_{r}(x, y)\right)\right]
$$

Son işlem olarak, yansıtma ve tasarlanmış aydınlatma sentezlenerek iyileştirilmiş görüntü elde edilmektedir (14).

\subsection{Füzyon Tabanı İyileştirme Metodu (Multi-scale Fusion Enhancing Method MF)}

Fu ve arkadaşlarının 2016 yılında önerdikleri füzyon esaslı çalışmada üç renk kanalından maksimum değeri alınarak bulunan aydınlatma ilk olarak, morfolojik kapama işlemi ile aydınlatmanın yeniden tasarımı gerçekleştirilmektedir.

$I=\frac{L \circ P}{255}$

Eşitlik (16) da ki P yapı elemanı ve o sembolü ise morfolojik kapama işlemini temsil etmektedir. Eşitlik (16) ya göre aydınlatma etkili bir şekilde tahmin edildikten sonra görüntü içerisindeki dış hatların şekillerini korumak için guided filtresine sokulmaktadır.

$I_{i} \leftarrow \sum_{j} W_{i j}(g) I_{j}$

Eşitlik de ki $W_{i j}$ guided filtresinin çekirdek değerleri, j ise pencere içerisindeki pikselleri temsil etmektedir. Yukarıda elde edilen aydınlatma kullanılarak füzyon işlemi için üç farklı giriş elde edilmiştir. İlk giriş bozulmalardan kaçınmak ve görüntünün orijinal yapısını korumak için orijinal tahmin edilen aydınlatmadır. İkinci giriş, görüntünün karanlık bölgelerinin netleştirmek için arc tanjant dönüşümü global aydınlatma amaçlı olarak kullanılmıştır. Eşitlik (18) de dönüşümün matematiksel ifadesi verilmiştir.

$I_{2}(x, y)=\frac{2}{\pi} \arctan (\lambda I(x, y))$

Eşitlik de ki $\lambda$ aydınlatmanın derecesini kontrol eden parametredir.

Üçüncü ve son giriş olarak ise yerel kontrast ayarı yapmak için Contrast Local Adaptive Histogram Equalization (CLAHE) kullanılmıştır.

$\mathrm{Bu}$ üç girişin hangi oranda kullanılacağını belirlemek için parlaklık ağırlığı $W_{B}$ ve $W_{C}$ kromatik kontrast ağırlığı kullanılmıştır.

$$
\begin{aligned}
& W_{B, k}(x, y)=\exp \left\{-\frac{\left(I_{k}(x, y)-0.5\right)^{2}}{2(0.25)^{2}}\right\} \\
& W_{C, k}(x, y)=I_{k}(x, y)(1+\cos (\alpha H(x, y)+\emptyset) S(x, y))
\end{aligned}
$$


Eşitlik (19) ve (20) de ki k kullanılan üç girişi, Eşitlik (20) deki H ve S HSC renk uzayındaki ton ve doygunluk kanallarıdır. Ayrıca $\alpha$ renk karşıtlığını korumak için, $\emptyset$ ise renk çarkının ofset açısını temsil etmektedir. Bu iki ağırlık $W_{k}(x, y)$ çatısında birleştirildikten ve normalleştirildikten sonra çok ölçekli füzyon işlemi Eşitlik (21) de ki gibi gerçekleştirilmektedir.

$I_{\text {fusion }}(x, y)=\sum_{k} W_{k}(x, y) I_{k}(x, y)$

Eşitlik (21) $W_{k}$ ağırlık değeri için Gaussian piramidi, $I_{k}$ için ise Laplas piramidi kullanıldıktan sonra yukarı yönde örnekleme operatörü kullanılarak füzyon işlemi geliştirilmiş ve güçlendirilmiştir. Son işlem olarak, elde edilen $I_{\text {final }}$ aydınlatma çıktısı ile üç kanalın yansıtma görüntüleri dengelenerek iyileştirilmiş görüntü elde edilmektedir (16).

\subsection{Basit ve Etkili Düşük Işık İyileştirme Algoritması (Low-light Image Enhancement LIME)}

Guo ve arkadaşları 2017 yılında basit ama etkili düşük ışık iyileştirme algoritması önermişlerdir. Yansıtma ve aydınlatma bileşenlerini içeren bir görüntüyü ayrıştırmayı hedefleyen geleneksel Retinex metotlarından en belirgin farkı çözüm uzayını daraltmak ve hesaplama karmaşıklığını azaltmak için sadece aydınlatmayı tahmin etmeye çalışmasıdır (17). Bunun için Eşitlik (22) de yer alan başlangıç aydınlatmasını esas alan optimizasyon fonksiyonu kullanılmıştır.

$\min _{I}\|\hat{T}-T\|_{F}^{2}+\alpha \| W$ o $\nabla T \|_{1}$

İlk olarak her bir piksel için R, G ve B kanalları içindeki maksimum değer bulunarak aydınlatma tasarımı gerçekleştirilir. Bu işlem Eşitlik (22) de, $\widehat{T}$ görüntünün ilk yapılan aydınlatma tasarımı olarak geçmektedir. Aynı şekilde, $\alpha$ iki terim arasında denge sağlama katsayısı, $W$ ağrılık matrisi, $\nabla T$ birinci dereceden türev filtresini temsil etmektedir.

Yukarıda verilen optimizasyon problemi iki farklı şekilde çözülmüştür. Exaxt-Solver adını verdikleri ilk çözümde, aydınlatma tasarımını yeniden düzenlemek için Augmented Lagrangian Multiplier (ALP) kullanılmıştır.

Sped-Up-Solver adı verilen ikinci çözümde direk olarak aydınlatmanın yeniden düzenlenmesi için Eşitlik (23) kullanılmıştır.

$$
\left(I+\sum_{d \in\{u, v\}} D_{d}^{T} \operatorname{Diag}\left(\overline{w_{d}}\right) D_{t}\right) t=\hat{t}
$$

Eşitlik (23) de ki $\widetilde{W}_{d}$ ağırlığın vektörize edilmiş durumunu, Diag(x) operatörü ise x vektörünü kullanarak köşeğen bir matris oluşturmak için kullanılmıştır. Eşitlik (23) de ki bütün yaklaşım Laplacian matris olarak tanımlanmış olup, simetrik pozitif özelliğe sahiptir.

Algoritma 1. LIME’nin çalışma algoritması

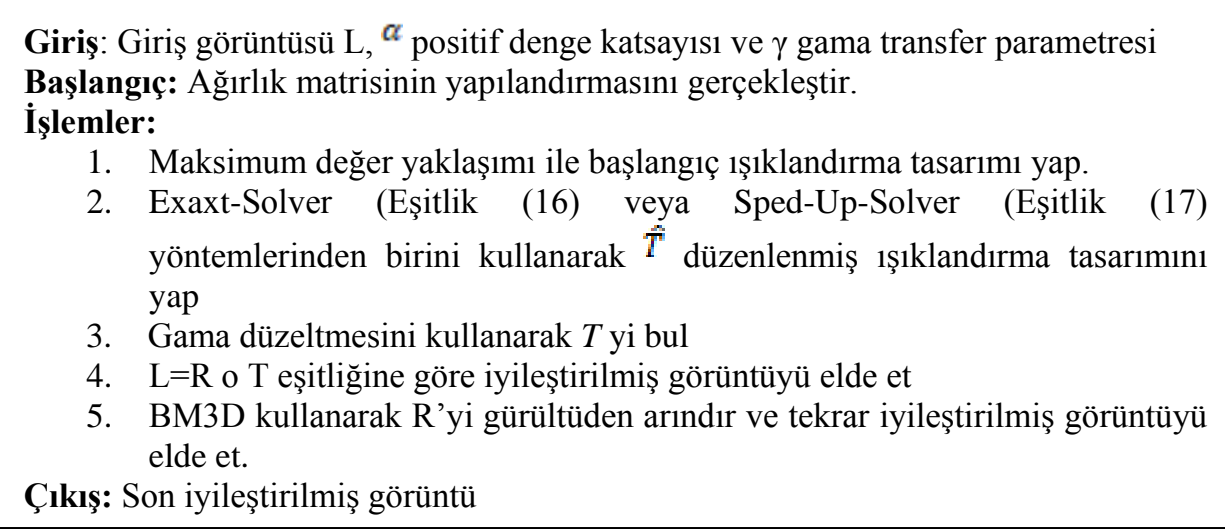

Aydınlatmanın tahmininden sonra, aydınlatmanın görselliğinin geliştirmek için gama düzeltmesi kullanılmıştır. Algoritma 1 de verildiği gibi gama düzeltmesinden sonra, BM3D gürültü giderme filtresine sokularak gürültüden arındırılmış yansıtma bileşeni elde edilmiştir (17). 


\subsection{Ortak İçsel-Dışsal Öncelikli Model (Joint Intrinsic-Extrinsic Prior Model, JieP)}

Xu ve arkadaşlarının 2017 de sundukları içsel ve dışsal öncelikli Retinex modelinde, doğrusal alan içinde aydınlatma ve yansıtma aynı anda ayrışabilen özelliktedir. Çalışmanın ilk bölümünde yerel varyasyon sapması adı verilen özellik ile içsel özellikler içinde yer alan yapının korunması amaçlanmıştır.

$R_{x / y}=\left|\frac{\nabla_{x / y} I}{\frac{1}{|\Omega|} \sum_{\Omega} \nabla_{x / y} I+\varepsilon}\right|$

Eşitlik (24) de verilen yerel varyasyon sapmasında, $\nabla_{x / y}$ eğim operatörünü, $\Omega$ görüntüden alınan yerel parçayı temsil etmekte olup, çalışma içerisinde $3 \times 3$ büyüklüğündedir. Ayrıca $\varepsilon$ sıfıra bölümden kaçınmak için kullanılan küçük bir sayıdır (18).

Algoritma 2 de verildiği gibi Eşitlik (25) göre aydınlatma için $u_{x / y}$, yansıtma için $v_{x / y}$ ağırlık değerleri ve ilk döngü de ki yansıtma $I_{l}$ ise Eşitlik (26) ya göre hesaplanır.

$\left\{\begin{array}{c}u_{x / y}=\left(\left|\frac{1}{\Omega} \Sigma_{\Omega} \nabla_{x / y} I\right|\left|\nabla_{x / y} I\right|+\varepsilon\right)^{-1} \\ v_{x / y}=\left(\left|\nabla_{x / y} R\right|+\varepsilon\right)^{-1}\end{array}\right.$

$(P 1) I_{k}=\operatorname{argmin}\left\|I \cdot R_{k-1}-S\right\|_{2}^{2}+\alpha\left(u_{x}\left\|\nabla_{x} I\right\|_{2}^{2}+u_{y}\left\|\nabla_{y} I\right\|_{2}^{2}\right)+\lambda\|I-B\|_{2}^{2}$

Eşitlik (26) da ki $S$ orijinal giriş görüntüsünü, $B$ parlak kanal olup, $\max _{\Omega}\left(\max _{\subset \in[r, g, b]} S^{c}\right)$ alınan görüntü parçacı̆̆ının maksimum renk değeri olarak elde edilmiştir. İlk döngüde yansıtmanın başlangıç değeri olan $R_{0}$ da bulunduktan sonra Eşitlik (27) kullanılarak $R_{I}$ güncellenmektedir.

$(P 2) R_{k}=\operatorname{argmin}\left\|I_{k} \cdot R-S\right\|_{2}^{2}+\beta\left(v_{x}\left\|\nabla_{x} R\right\|_{2}^{2}+v_{y}\left\|\nabla_{y} R\right\|_{2}^{2}\right)$

Algoritma 2. JieP'in çalışma algoritması

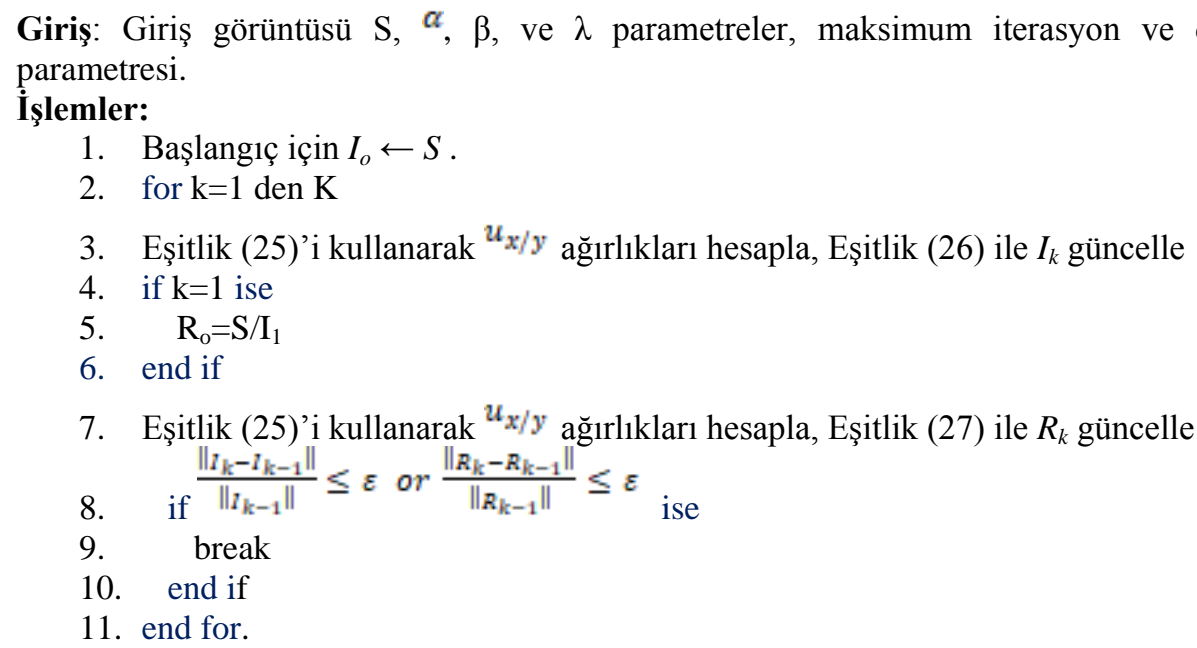

Görüntü iyileştirme için gerçekleştirilen optimizasyon işlemi Algoritma 2 de ki 8. Satırda ki şart gerçekleşme durumunda sonlanmaktadır. Son döngü de elde edilen $I_{k}$ ve $R_{k}$ görüntüleri kullanılarak iyileştirilmiş görüntü elde edilmektedir.

\subsection{Yapı Ortaya Çıkaran Düşük Işıklı İyileştirme Metodu (Structure-Revealing Low-Light Image Enhancement Via Robust Retinex Model, RRM)}

$\mathrm{Bu}$ metodun en önemli özelliği, eş zamanlı olarak yapıyı ortaya çıkartan yansıtma ve alternatif optimizasyon fonksiyonu kullanılarak gürültülerden arındırılmış aydınlatma tahminlerini yapmasıdır. Giriş olarak verilen görüntü ilk olarak HSV uzayına dönüştürülerek başlanır. V kanala önerilen ayrıştırma algoritması uygulanarak, aydınlatma bileșeni L ve yansıtma bileşeni R elde edilmektedir (19). Alternatif ayrıştırma adı verilen bu 
yöntemde gürültünün dağılımını tahmin etmek yerine giriş görüntüsünde gürültü haritası tahmini gerçekleştirilmiştir. Yöntemin optimizasyon problemi Eşitlik (28) de verilmiştir.

$\underset{R, L, N}{\operatorname{argmin}}\|R o L+N-I\|_{F}^{2}+\beta\|\nabla L\|_{1}+\omega\|\nabla R-G\|_{F}^{2}+\delta\|N\|_{F}^{2}$

Eşitlikteki $N$ gürülttü haritasıdır ve $\|N\|_{F}^{2}$ gürültünün genel yoğunluğunu sınırlamaktadır. $\beta, \omega$ ve $\delta$ farklı terimlerin önem derecesini kontrol eden katsayılardır. $\|\quad\|_{F}^{2}$ ve $\|\quad\|_{1}$ Frobenis ve $l_{l}$ matris normların temsil etmektedir. Ayrıca $\nabla$ birinci dereceden diferansiyel operatörü, $G$ ise $I$ görüntüsünün gradyanı temsil etmektedir.

Algoritma 3. RRM'in çalışma algoritması

Giriş: Giriş görüntüsü $I$ ve $G$ ayarlanmış gradyan

Başlangıç: $\mathrm{L}^{(0)}=I, \mathrm{~N}^{(0)}=\mathrm{Z}^{(0)}=\mathrm{T}^{(0)}=0, k=0,{ }^{\mu(0)}=1$ ve ${ }^{\rho}=1.5$.

İşlemler:

while yakınsama yoksa do .

Eşitlik (29) kullanarak $\mathrm{R}^{(\mathrm{k}+1)}$ güncelle

Eşitlik (30) kullanarak $\mathrm{L}^{(\mathrm{k}+1)}$ güncelle

Eşitlik (31) kullanarak $\mathrm{N}^{(\mathrm{k}+1)}$ güncelle

Eşitlik (32) kullanarak $T^{(\mathrm{k}+1)}$ güncelle

Eşitlik (33) kullanarak $Z^{(\mathrm{k}+1)}$ güncelle

$k=k+1$;

end

Cıkıs: $\mathrm{IR}^{(\mathrm{k})}, \mathrm{L}^{(\mathrm{k})}, \mathrm{N}^{(\mathrm{k})}$

$r^{(k+1)}=\left(f\left(\tilde{I}^{(k)}\right)+\omega f(D)\right)^{-1}\left(\tilde{I}^{(k)}\left(i-n^{(k)}+\omega D^{T} g\right)\right.$

Eşitlik (29) da ki D ayrı gradyan operatörünü temsil etmektedir. Aydınlatmanın güncellemesi ise Eşitlik (30) a göre yapılmaktadır.

$l^{(k+1)}=\left(2 f\left(\tilde{r}^{(k+1)}\right)+\mu f(D)\right)^{-1} x\left(2 \tilde{r}^{(k+1)}\left(i-n^{(k+1)}+\mu D^{T}\left(t^{(k)}-\frac{z^{k}}{\mu}\right)\right)\right.$

$\left.N^{(k+1)}=\left(I-R^{(k+1)} o L^{(k+1)}\right) /(1+\delta)\right)$

$T^{(k+1)}=S_{\frac{\beta}{\mu(k)}}\left(\nabla L^{(k+1)}+\frac{Z^{(k)}}{\mu(k)}\right)$

$Z^{(k+1)}=Z^{(k)}+\mu(k)\left(\nabla L^{(k+1)}-T^{(k+1)}\right)$

$\mu^{(k+1)}=\mu^{(k)} \rho, \rho>1$

Algoritma 3. incelendiğinde, her döngüde sırasıyla $\mathrm{R}, \mathrm{L}, \mathrm{N}, \mathrm{T}$ ve $\mathrm{Z}$ değerleri güncellenmektedir. L çıkışı gama düzeltmesi ile yeniden ayarlanır ve $\hat{I}=R o \widehat{L}$ eşitliği kullanılarak iyileştirilmiş $\mathrm{V}$ kanal görüntüsü elde edilmiştir. Son olarak HSV renk uzayından RGB ye geçilerek iyileştirilmiş çıkış görüntüsü sunulmaktadır (19).

\subsection{Düşük Sıralı Düzenlenmiş Retineks Modeli (Low-Rank Regularized Retinex Model, LR3M)}

LR3M retineks modelinin en temel özelliği yansıtma haritasındaki gürültüyü bastırmak için retineks ayrıştırma işlemi içerisine öncelikli düşük sıralı mantığının yerleştirilmesidir. Önerilen metot parça bazlı düzleştirilmiş aydınlatma ve bastırılmış gürültülü yansıtma bileşenlerini sunmaktadır (20). Önerilen çalışma da ilk olarak, başlangıç aydınlatma bileşeninin tahmini için aşağıdaki eşitlik kullanılmıştır.

$\widehat{L}(x)=\frac{1}{3} \sum_{c \in\{R, G, B\}} S^{c}(x)$

Başlangıç aydınlatma kullanılarak görüntünün aydınlatma bileşeninin tahmini Eşitlik (35) de verilmiştir.

$\underset{L}{\operatorname{argmin}}\|L-\widehat{L}\|_{F}^{2}+\alpha \sum_{x} \sum_{d \in\{h, v\}} \frac{\left(\nabla_{d} L(x)\right)^{2}}{\left|\nabla_{d} \widehat{L}(x)\right|+\varepsilon}$ 
Eşitlik (35) deki $\frac{\pi}{\left.\mid \nabla_{d} \widehat{L}(x)\right]+\varepsilon}$ ifadesine kısaca $A_{d}(x)$ denildikten sonra, bu ikinci dereceden terimler içeren ifadenin diferansiyel işlemleri yapılması ile birlikte Eşitlik (36) ile $L$ aydınlatma tahmini kolay bir şekilde elde edilmektedir.

$\mathrm{l}=\left(I+\sum_{d \in\{h, v\}} D_{d}^{T} \operatorname{Diag}\left(a_{d}\right) D_{d}\right)^{-1} \hat{l}$

Yansıtmanın tahmini için Rahman ve arkadaşlarının sundukları orijinal minimizasyon problemi (10) standart alternatif yön minimizasyon çözüm tekniği kullanılarak gerçekleştirilmiştir.

$\hat{r}^{(k+1)}=\left(2 \beta \sum_{d \in\{h, v\}} D_{d}^{T} D_{d}+\mu I\right)^{-1} x\left(2 \beta \sum_{d \in\{h, v\}} D_{d}^{T} g_{d}+\mu^{(k)} r^{(k)}-z^{(k)}\right)$

Eşitlik (37) de ki $D$ ayrık gradyan operatörünü, $x$ ise matris çarpımının gerçekleştirildiğini temsil etmektedir. Gürültü bastırma işlemi için standart düşük sıralı minimizasyon problemi eklenerek yansıtma tahmini Eşitlik (38) de tekrar güncellenmiştir.

$\bar{R}^{(k)}=\frac{2 \operatorname{SoL}+\mu(k) \hat{R}^{(k+1)}+Z^{(k)}}{2 L^{2}+\mu(k)}$

$N N_{i}\left(R^{(k+1)}\right)=\left(S_{T}\left(\bar{R}^{(k)}\right)\right)$

Eşitlik (38) deki $S_{T}$ ifadesi yumuşak çekme işlemi yaparak gürültü bastırmayı gerçekleştirmektedir. Eşitlik teki diğer $Z^{(k+1)}$ yardımcı matris ve $\mu^{(k+1)}$ ceza skalerinin güncellemeleri Eşitlik (39) içerisinde sunulmuştur.

$Z^{(k+1)}=Z^{(k)}+\mu(k)\left(\hat{R}^{(k+1)}-R^{(k+1)}\right)$

$\mu^{(k+1)}=\mu^{(k)} \rho, \rho>1$

Algoritma 4. LR3M' in çalışma algoritması

Giriş: Giriş görüntüsü $S$

Eşitlik (34) kullanılarak $\widehat{L}$ başlangıç ışıklandırma bileşenini elde et

Eşitlik (35) kullanılarak $L$ başlangıç 1şıklandırma tahminini elde et

$\mathrm{R}^{(0)}=\mathrm{S} / \mathrm{L} I, \mathrm{Z}^{(0)}=0, \mu^{(0)}=1, \rho=1.5$ ve $k=0$.

İşlemler:

while yakınsama yoksa do .

Eşitlik (37) kullanarak $\hat{\mathbb{R}}^{(\mathrm{k}+1)}$ güncelle

Eşitlik (38) kullanarak $\mathrm{R}^{(\mathrm{k}+1)}$ güncelle

Gürültü bastırma için

Eşitlik (39) kullanarak $Z^{(\mathrm{k}+1)}$ ve ${ }^{\mu(\mathrm{k}+1)}$ güncelle

end

Çıkış: Eşitlik (0) kullanılarak çıkış görüntüsünü elde et

$S^{\prime}=\operatorname{RoL}^{\prime}{ }^{\prime \frac{1}{\gamma}}$

Algoritma 4. incelendiğinde, her döngüde sırasıyla $R, Z$ ve $\mu$ değerlerini güncellenmektedir. Diğer algoritmalardan farklarından biri de $L$ döngüye girmeden tahmin edilmiştir. $L$ çıkışı gama düzeltmesi ile yeniden ayarlanmakta Eşitlik (40) kullanılarak iyileştirilmiş görüntü elde edilmiştir (20).

\subsection{Yapı ve Dokuya Duyarlı Retineks Model (A Structure and Texture Aware Retinex Model, STAR)}

$\mathrm{Bu}$ çalışma içerisinde üstel yerel türevler kullanılarak yapı ve doku haritalamaları üretilerek iyileştirme yapılmaya çalışılmıştır. Bunun için ilk olarak esnek yapı ve doku tahmini için yerel türevlerin üstel versiyonu (Exponentiated Mean Local Variance EMLV) önerilmiştir (21).

$f_{E M L V}(O)=f_{M L V}^{\gamma}(O)=\left|\frac{1}{|\Omega|} \sum_{\Omega} \nabla O\right|^{\gamma}$ 
Eşitlikte ki $\Omega$ görüntü içerisindeki alınan parçayı, $|\Omega|$ parçanın elaman sayısını ve $\gamma$ giriş görüntüsünün gradyan hassasiyetini belirleyen üstel değerdir. Bu filtre önerisinden sonra başlangıç için yapı ve doku tahmini aşağıda ki eşitliklerde verilmiştir.

$S_{O}=1 \oslash\left(\left|\frac{1}{|\Omega|} \sum_{\Omega} \nabla O\right|^{\gamma_{s}}+\varepsilon\right)$

$T_{O}=1 \oslash\left(\left|\frac{1}{|\Omega|} \sum_{\Omega} \nabla O\right|^{\gamma_{t}}+\varepsilon\right)$

Eşitlik (42) de ki $\gamma_{s}>1$ ve Eşitlik (43) de ki $\gamma_{t}<1$ seçilerek aydınlatma ve yansıtmanın ayrışması için yapı ve doku ayarlanması sağlanmaktadır.

STAR ile aydınlatma ve yansıtma bileşenlerinin yeniden düzenlenmesi için toplam varyasyon modelinin 12 normu benimsenmiştir, aşağıdaki eşitlikte sunulmuştur.

$\min _{L, R}\|O-L \odot R\|_{F}^{2}+\alpha\left\|S_{O} \odot \nabla L\right\|_{F}^{2}+\beta\left\|T_{o} \odot \nabla R\right\|_{F}^{2}$

Algoritma 5. STAR'ın çalı̧̧ma algoritması

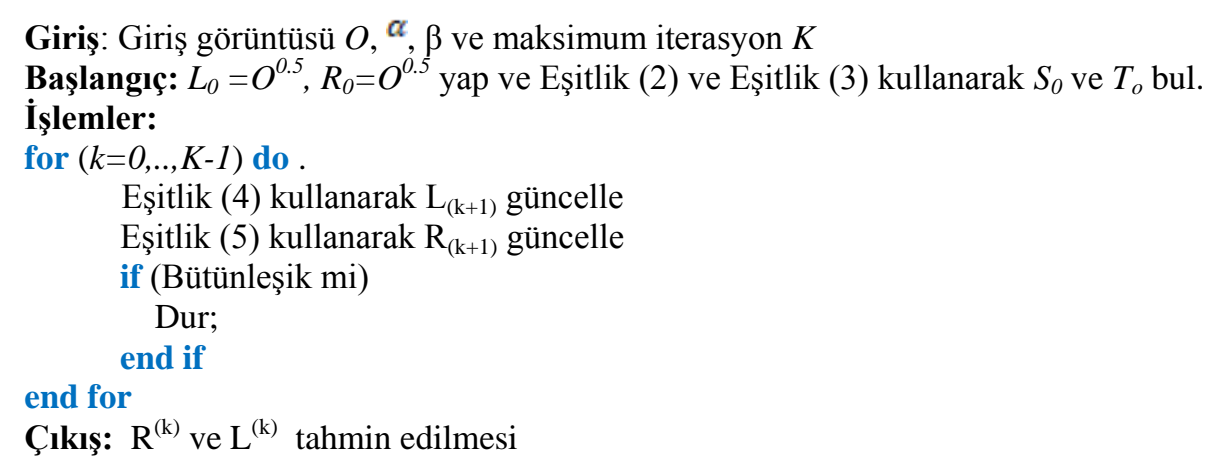

Algoritma 5. de verildiği gibi başlangıç değerleri kullanılarak Eşitlik (45) de yer alan aydınlatma ve Eşitlik (46) da yer alan yansıtma bileşenleri her döngüde güncellenmektedir.

$l_{k+1}=\left(D_{r k}^{T} D_{r k}+\alpha G^{T} D_{s o}^{T} D_{s o} G\right)^{-1} D_{r k}^{T} O$

$r_{k+1}=\left(D_{l k+1}^{T} D_{l k+1}+\beta G^{T} D_{t o}^{T} D_{t o} G\right)^{-1} D_{l k}^{T} O$

Eşitlik (5) ve Eşitlik (6) da ki $D_{r k}=\operatorname{diag}\left(r_{k}\right), D_{s o}=\operatorname{diag}\left(s_{o}\right), G l=v e c(\nabla L), D_{l k}=\operatorname{diag}\left(l_{k}\right), D_{t o}=\operatorname{diag}\left(t_{o}\right), G r=v e c(\nabla R)$ standart en küçük kareler regrasyon problemine dönüştürülmesi için kullanılmıştır (21).

\section{RETINEKS ESASLI ÇALIŞMALARDA KULLANILAN ÖLÇÜM METRÍKLERİ}

\subsection{Aydınlık Değişimi Sıra Hatası (Lightness Order Error, LOE)}

Bağıl açıklık düzeni ışık kaynağını ve aydınlık değişimini temsil ettiğinden iyileştirilmiş görüntünün doğallığı farklı lokal alanlar içindeki bağıl açıklık düzenlerine bağlıdır (14).

$L(x, y)=\max _{c \in[r, g, b]} I^{c}(x, y)$

Eşitlik (47) de üç renk kanalının değerinin maksimumu alınarak başlanır. Orijinal görüntü ile iyileştirilmiş görüntü arasındaki açıklık bağıl sıralama farkı Eşitlik (48) de sunulmuştur.

$R D_{(x, y)}=\sum_{i=1}^{m} \sum_{j=1}^{n}\left(U(L(x, y), L(i, j)) \oplus U\left(L_{e}(x, y), L_{e}(i, j)\right)\right)$

Eşitlik (48) de ki $m$ ve $n$ görüntünün yüksekliği ve genişliğini, $U(x, y)$ birim basamak fonksiyonunu, $\oplus$ işlemi ise özel veya operatörünü temsil etmektedir.

$U(x, y)=\left\{\begin{array}{cc}1, f \text { or } & x \geq y \\ 0, & \text { else }\end{array}\right.$ 
$\mathrm{Bu}$ durumda LOE Eşitlik (50) de verildiği gibi hesaplanmaktadır.

$L O E=\frac{1}{m * n} \sum_{i=1}^{m} \sum_{j=1}^{n} R D(i, j)$

LOE tanımından da anlaşıldığı gibi, küçük bir LOE değerinin elde edilmesi açıklık düzeni veya doğallığın daha iyi korunduğu anlamına gelmektedir (14).

\subsection{Gradyan Büyüklük Benzerlik Sapması (Gradient Magnitude Similarity Deviation, GMSD)}

Retinex esaslı görüntü iyileştirme çalışmaları içerisinde GMSD metriği ilk olarak Fu ve arkadaşlarının önerdiği MF metodu içerisinde kullanılmıştır (16). Bozulmuş görüntü içinde farklı yerel yapılar bozulmanın farklı derecelerine maruz kalırken, görüntü gradyanları görüntü bozulmalarına veya görüntü değişimlerine karşı hassastırlar. Bu özellik, genel görüntü kalitesinin tahmini için yerel kalite tasarımı esaslı gradyanın küresel varyasyonunun kullanımını sağlamıştır.

İlk olarak gradyanın büyüklük benzerliği olan Gradient Magnitude Similarity (GMS) değeri her bir piksel için Eşitlik (51) de yer aldığı gibi bulunur (24).

$\operatorname{GMS}(i)=\frac{2 m_{r}(i) m_{d}(i)+c}{m_{r}^{2}(i)+m_{d}^{2}(i)+c}$

Eşitlik (51) de ki $m_{r}$ ve $m_{d}$ sırasıyla o pikselin referans ve çıkış görüntülerinin gradyanlarıdır. Aynı şekilde $c$ değeri sayısal olarak istikrarı sağlamak adına pozitif sabit bir sayıdır. GMS değerini bulduktan sonra görüntü karşılaştırma için Gradient Magnitude Similarity Mean (GMSM) değeri Eşitlik (52) kullanılarak elde edilmektedir.

$G M S M=\frac{1}{N} \sum_{i=1}^{N} G M S(i)$

Eşitlik (52) de ki N değeri görüntü içerisindeki piksellerin toplam sayısını vermektedir. Açıkça görüldüğü üzere, GMSM’nin yüksek çıkması görüntü kalitesinin yüksek olduğu anlamına gelmektedir. Orijinal görüntüden fazla uzaklaşılmadığı şeklinde yorumlanabilir (24).

$G M S D=\sqrt{\frac{1}{N} \sum_{i=1}^{N}(G M S(i)-G M S M)^{2}}$

Son olarak gradyan büyüklük benzerlik sapması GMSD değeri Eşitlik (53) kullanılarak bulunmaktadır. Bu değerin küçük olması elde edilen çıkış görüntüsünün doğallığını koruduğu ve görüntü kalitesinin iyileştiği anlamına gelmektedir.

\subsection{Doğal Görüntü Kalite Değerlendiricisi (Natural Image Quality Evaluator, NIQE)}

Doğal görüntü kalite değerlendiricisi olan NIQE, uzaysal domain içinde gerçekleştirilen basit ve başarılı doğal sahne istatistiğine (Natural Scene Statistic (NSS)) dayalı istatiksel özelliklerin toplanmasıyla oluşturulan bir yapıya sahiptir (25). Doğal görüntülerin düşük sıralı istatiksel değerleri etkili bir şekilde yakalanmasını sağlayan yerel görüntü parçalarından elde edilmiştir.

$\hat{I}(i, j)=\frac{I(i, j)-\mu(i, j)}{\sigma(i, j)+1}$

Eşitlikteki $\mu$ ve $\sigma$ yerel ortalama ve normalizasyon işlemini için varyasyon alanını temsil etmektedir. Eşitlik (8) de ki katsayılar hesaplandıktan sonra görüntü $P x P$ yamalara bölünmektedir. $P x P$ yamalar $b=1,2, \ldots, B$ şeklinde indekslendiğini düşünürsek, her bir parçanın ortalama yerel sapma alanı aşağıda verilen eşitlikte hesaplanmaktadır.

$\delta(b)=\sum \sum_{(i, j) \in \operatorname{patch} b} \sigma(i, j)$

Eşitlikte ki $\delta$, yerel keskinlik aktivitesi olarak tanımlanmıştır. Her yamanın keskinliği bulunduğunda, eşik üstü keskinliğe sahip olanlar seçilmektedir.

Komşuluk katsayılarının üretimi asimetrik genelleştirilmiş Gaussian dağılımı (Asymmetric Generalized Gaussian Distribution (AGGD)) kullanılarak modellenmiş̧ir. 
$f\left(x ; \gamma, \beta_{l}, \beta_{r}\right)=\left\{\begin{array}{l}\frac{\gamma}{\left(\beta_{l}+\beta_{r}\right) \Gamma\left(\frac{1}{\gamma}\right)} \exp \left(-\left(\frac{-x}{\beta_{l}}\right)^{\gamma}\right) \quad \forall x \leq 0 \\ \frac{\gamma}{\left(\beta_{l}+\beta_{r}\right) \Gamma\left(\frac{1}{\gamma}\right)} \exp \left(-\left(\frac{-x}{\beta_{r}}\right)^{\gamma}\right) \forall x \geq 0\end{array}\right.$

Eşitlikte ki $\Gamma$ gama fonksiyonunu olup $\operatorname{AGGD}\left(\gamma, \beta_{l}, \beta_{r}\right)$ etkili bir şekilde tahmin edilmektedir. Eşitlik (56) dan $\left(x_{1}, . ., x_{k}\right)$ NSS özellikleri hesaplandıktan sonra, çok değişkenli Gaussian modeline (Multivariate Gaussian (MVG) uydurarak zengin bir temsil imkanı sağlanmıştır. MVG uydurma işlemi Eşitlik (57) de verilmiştir.

$f x(x 1, \ldots, x k)=\frac{1}{(2 \pi)^{k / 2}|\Sigma|^{1 / 2}} * \exp \left(-\frac{1}{2}(x-v)^{T} \Sigma^{-1}(x-v)\right)$

Eşitlikte ki $v$ ve $\Sigma$ sırasıyla MVG modelinin ortalama ve kovaryans matrisini temsil etmektedir. Sonuç olarak NIQE modelinde çıkış görüntüsünün kalitesi NSS özellik modeli ile MVG’ye uydurularak elde edilen özellikler arasındaki mesafe olarak ifade edilmiştir ve Eşitlik (58) de sunulmuştur (25).

$D\left(v_{1}, v_{2}, \Sigma_{1}, \Sigma_{2}\right)=\sqrt{\left(\left(v_{1}-v_{2}\right)^{T}\left(\frac{\Sigma_{1}+\Sigma_{2}}{2}\right)^{-1}\left(v_{1}-v_{2}\right)\right)}$

Eşitlikte ki $v_{1}, v_{2}$ ve $\Sigma_{1}, \Sigma_{2}$ doğal ve çıkış görüntüsünün ortalama vektörleri ve kovaryans matrislerini temsil etmektedir. NIQE metriği mesafe özellikli olmasından dolayı küçük değerlere sahip sonuçların doğal görüntüye yakınlığının daha iyi olduğu sonucu çıkartılmaktadır. Bu metriğin retineks esaslı çalışmalarda ilk olarak tercih edilmesi Fu ve arkadaşlarının 2016 yılında önerdikleri füzyon esaslı uygulamada gerçekleşmiştir (16).

\subsection{Otoregresif Görüntü Netlik Metriği (Autoregressive-based Image Sharpness Metric, ARISM)}

Gu ve arkadaşlarının 2015 yılında sundukları ARISM metriği adlı çalışmalarında, otoregresif esaslı olup görüntülerin keskinliğinin ölçümünde kullanılmak üzere amaçlanılmıştır. Belirli bir piksele karşıllık gelen otoregresif parametrelerinin yüksek benzerlik değerlerinin oluşması, o konumun daha zayıf keskinliğe sahip olduğu anlamına gelmektedir. İlk adım olarak her bir piksel için otoregresif model katsayılarının tahmin edilmesidir. Bunun için her bir piksel ve onun 8 bağlantılı komşuluğu için 8 'inci sıra otoregresif modeli eğitilmiştir (26).

Bu parametreler üzerinde çalışılan piksel keskin bir bölgeye ait olması durumunda, farklı olma eğilimi gösterirler. Bunun için iki farklı ölçü seçilmiştir. Birincisi otoregresif parametrelerin maksimum ve minimum farklarını alır ve Eşitlik (59) da verilmiştir.

$E_{i, j}=\left|W_{\max }-W_{\text {min }}\right|^{n}$

$W_{\max }$ ve $W_{\min }$ otoregresif parametrelerden çıkartılan maksimum ve minimum değer olup, $n$ farkın öneminin ayarlamak için kullanılan üstel değerdir. Kontrast esaslı diğer yerel keskinlik ölçümü, Eşitlik (60) da verilmiştir.

$C_{i, j}=\frac{\left(W_{\max }-W_{\min }\right)^{2}}{W_{\max }^{2}+W_{\min }^{2}}$

Eşitlik (59) ve (60) da ki $E$ ve $C$ değerleri $E^{b b}$ ve $C^{b b}$ blok esaslı parça bölgelerin enerji ve kontrast hesaplamaları yapıldıktan sonra, keskinlik skoru hesaplaması Eşitlik (61) de ki gibi yapılmaktadır.

$\rho=\sum_{k \in \Psi} \Theta_{k} \cdot \rho_{k}$

Eşitlikteki $\rho_{k}$ keskinlik skoru $\mathrm{k} \in\left\{E, C, E^{b b}, C^{b b}\right\}$ içerisindeki en yüksek değerlerin ortalaması olarak alınmaktadır. Ayrıca $\Psi=\left\{E, C, E^{b b}, C^{b b}\right\}$ olup, $\Theta_{k}$ her bir kompenentin bağıl öneminin ayarlamak için kullanılan positif bir sabittir. ARISM'den elde edilen keskinlik skoru değeri ne kadar küçük ise görüntünün keskinlik kalitesinin yüksek olduğu sonucu çıkartılmaktadır (26). Retineks esaslı görüntü işleme uygulamalarında bu metriğin ilk kullanımı Cai ve arkadaşlarının 2017 de sunmuş oldukları JieP adlı çalışmada yer almıştır (18).

\subsection{Kör Ton Eşlemeli Kalite İndeksi (Blind tone-mapped Quality Index, BTMQI)}

Gu ve arkadaşlarının 2016 yılında sundukları BTMQI ölçme metriğinde, bilgi, doğallık ve yapı özelliklerinin analizi gerçekleştirilmiştir (27). Öncelikle giriş ton eşlemeli görüntünün orijinal aydınlığını koyulaştırarak ve aydınlatarak bir dizi ara görüntüler kümesinin entropi bilgisini ölçerek başlanılmıştır.

$E_{t}\left(I_{i}\right)=\omega E_{g}\left(I_{i}\right)+(1-\omega) E_{l}\left(I_{i}\right)^{v}$ 
Eşitlikte ki $E_{g}\left(I_{i}\right)$ ve $E_{l}\left(I_{i}\right)$ sırasıyla global ve yerel entropi değerlerini gösterirken, $\omega$ ve $v$ iki bileşenden oluşan entropi verilerinin göreceli önemini değiştirmek için kullanılmıştır. Çalışma içerisinde pozitif sabit değerlerde olup, 0.59 ve 1.5 olarak alınmaktadır.

İkinci işlem olarak algısal kalitenin ölçülebilmesi için doğal görüntü istatik verilerinden ton eşlemeli görüntünün ayrıştırılması düşünülmüştür.

$$
\begin{aligned}
& P_{m}(m)=\frac{1}{\sqrt{2 \pi \sigma_{m}}} \exp \left[-\frac{m-\mu_{m}}{2 \sigma_{m}^{2}}\right] \\
& P_{d}(d)=\frac{(1-d)^{\beta_{d}-1} d^{\alpha_{d}-1}}{B\left(\alpha_{d}, \beta_{d}\right)}
\end{aligned}
$$

Eşitlik (63) de ki $m$ ve Eşitlik (64) de ki $d$ 11x11 boyutlarındaki her bir parçanın global ortalama ve standart sapma değerlerini temsil etmektedir. Eşitlik (63) Gaussian fonksiyonu ile Eşitlik (64) Beta olasılık yoğunluk fonksiyonu $B($.) ile iki histogram elde edinimi sağlanarak görüntü yoğunluk ve kontrast ölçümü amaçlanmıştır. Eşitliklerde ki $\mu_{m}=115.94, \sigma_{m}=27.99, \alpha_{d}=4.4$ ve $\beta_{d}=10.1$ olacak şekilde model parametreleri seçilmiştir. İkinci bölümün son nihai eşitliği doğallık ölçümü olarak Eşitlik (65) de verilmiştir.

$N=\frac{1}{K} P_{m} P_{d}$

Eşitlikte ki K normalleştirme faktörü olup, $K=\left\{P_{m} P_{d}\right\}$ şeklinde bulunmaktadır.

Üçüncü olarak, ton ayrıştırmalı görüntü içerisinden temel yapıları belirlemek için sabit eşikli Sobel operatörü kullanılmıştır.

$X(n)=\left\{\begin{array}{c}1, \text { if } G(n) \geq T \\ 0, \text { otherwise }\end{array}\right.$

Eşitlikte ki $G(n)$ Sobel operatörü sonucu çıkan görüntünü gradyan büyüklüğü, $T$ eşik değer olup, çalışma içerisinde 0,05 olarak alınmıştır.

Son olarak BTMQI'ın genel kalite puanını elde etmek için gerçekleştirilen bu üç özelliği birleştirme işleminde eğitilmiş regrasyon modeli kullanılmıştır (27). Diğer ölçüm metotlarında olduğu gibi bu değerinde küçük çıkması, iyileştirilmiş görüntünün kalite indeksinin yüksek olması şeklinde yorumlanmaktadır. Retineks esaslı görüntü işleme uygulamalarında bu metriğin ilk kullanımı Li ve arkadaşlarının 2018 de sundukları çalışmada yer almıştır (19).

\section{DENEYSEL SONUÇLAR VE PERFORMANS ANALIZLERİ}

Retineks esaslı yöntemlerin performanslarını farklı açılardan değerlendirmek için, deneylerimizde Guo ve arkadaşlarının uyguladıkları düşük ışıklı veri tabanı ile Cai ve arkadaşlarının tercih ettikleri veri tabanı kullanılmıştır (17) (18). Bu veri tabanında kullanılan görüntüler farklı boyutlarda, 24 bit derinliği ve bmp formatı özelliklerine sahiptir. Bu görüntülerden düşük ışık seviyesi en kötü 10 görüntü seçilmiştir. Çalışmada kullanılan düşük 1ş1klı görüntüler Şekil 2. de verilmiştir. Uygulama MATLAB R2018a sürümünde Intel (R) Core (TM) i54200U CPU $2.30 \mathrm{GHz}$ processor ve 6 GB Ram bilgisayarında gerçekleştirilmiştir.

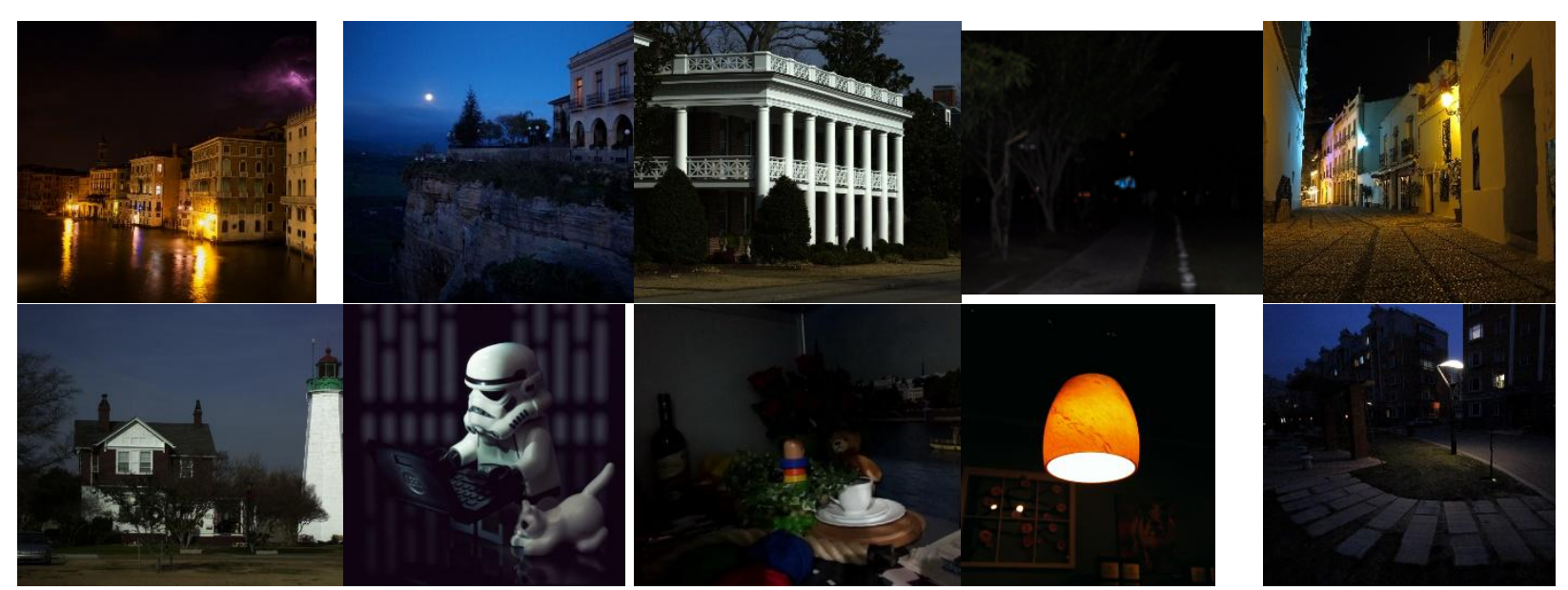

Şekil 2. Çalışmada kullanılan düşük 1şıklı görüntüler (17) (18). 


\section{1. İyileştirilmiş Görüntülerin Sübjektif Değerlendirilmesi}

Şekil 3 ve 4 de, düşük 1şıklı renkli test görüntülerinin iyileştirilmesi ile elde edilen görsel sonuçlara yer verilmiştir. Şekil 3. (a), (b), (c) ve Şekil 4. (a), (b), (c) görüldüğü gibi SSR, MSR ve MSRCR yöntemlerinde görüntü yansıtma bileşeni olarak alınmıştır. $\mathrm{Bu}$ nedenle bu çalışmalarda görüntüler doğal değildir ve aşırı iyileşme sorunu çalışılan bütün görüntülerde sıklıkla görülmüştür.

Şekil 3. (d), (e) ve Şekil 4. (d), (e) görüldüğü gibi NPE ve MF yöntemlerinde kontrast artışı az oranda gerçekleşmiş̧ir. Diğer görüntülere göre daha koyu bir görünüşe sahiptirler. NPE yapılan görsel karşılaştırma analizine göre, hem verimlilik hem de görsel kalite açısından diğer yöntemlere göre daha az etkileyici performans göstermiştir. MF'nin performansı bir çok görüntüde performansı umut vericidir. Ancak aydınlatma yapısının körlüğü nedeniyle MF, zengin dokuya sahip bölgelerin gerçekçiliğini kaybetme riskine sahiptir.

Şekil 3. (i) ve Şekil 4. (i) de görüntülerin tamamında bulanık bir yapı etken durumdadır. Bu durum ayrıntıların kaybolmasına sebep olmuştur. RRM yönteminin aydınlatma bileşeninin pürüzsüz varsayılması, yansıtma haritasında gözlenebilir gürültülere yol açmıştır. Bu dezavantajı ortadan kaldırmak için alternatif bir yön küçültme algoritması kullanmak, gürültünün hem aydınlatma hem de yansıma haritalarının tahminini bozmasına neden olmuştur.

Şekil 3. (h), (k) ve Şekil 4. (h), (k) görüldüğü gibi JieP ve STAR yöntemlerinde görüntü kontrastı geniş ve detaylar daha düzgün şekilde iyileştirme sağlanmıştır. Görüntü içerisindeki kenar ve bölge bilgilerinin daha belirgin olduğu görülmektedir.

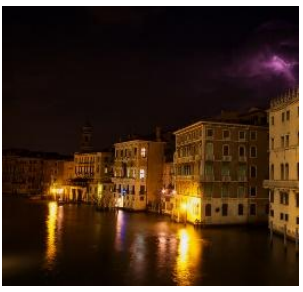

a) Orijinal

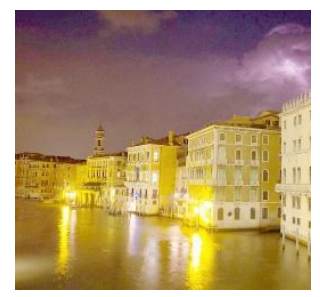

b) SSR

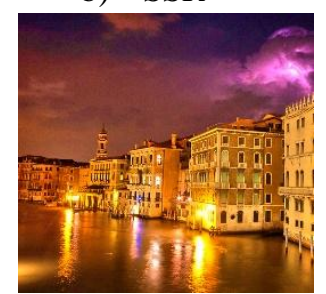

g) LIME

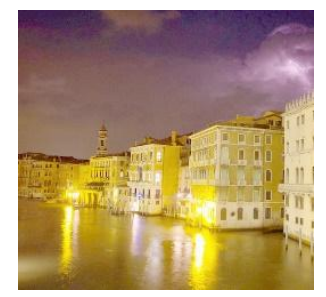

c) MSR

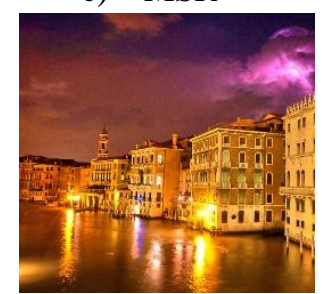

h) JieP

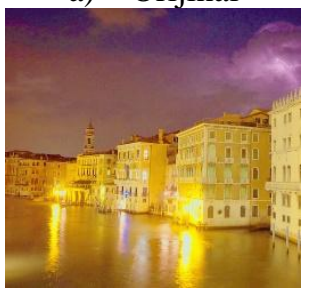

d) MSRCR

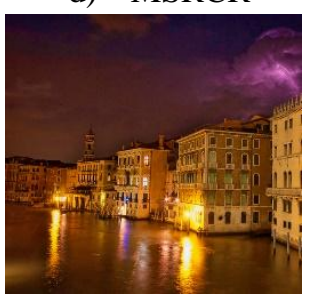

i) RRM

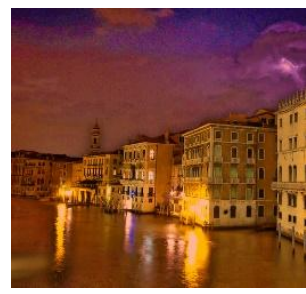

e) NPE

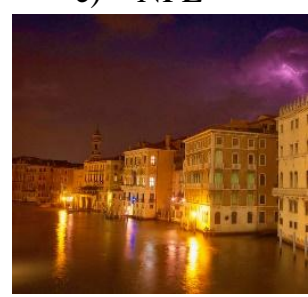

j) LR3M

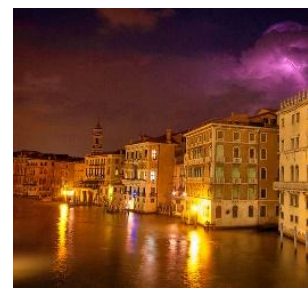

f) $\mathrm{MF}$

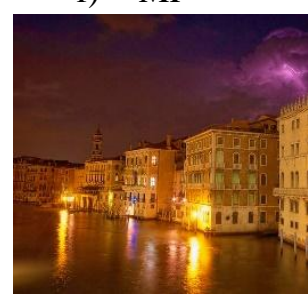

k) STAR

Şekil 3. Çalışmada kullanılan 1 numaralı düşük 1şıklı görüntünün iyileştirme sonuçları.

Sübjektif gözlem sonucunda, Şekil 3. (g), (j) ve Şekil 4. (g), (j) de ki LIME ve LR3M yöntemlerinin işlevsel bir yöntem oldukları sonucuna varılmıştır. Çünkü sadece kontrast ve detay bilgisi arttırmak için mükemmel bir performansa sahip olmakla kalmamış, keskinlik ve açıklık başarılı bir şekilde gerçekleştirilmiştir. Bunlara ilaveten LR3M de filtreleme işlemi çok iyi bir şekilde yapıldığı gürültülerin yok edilmesinden anlaşılmaktadır.

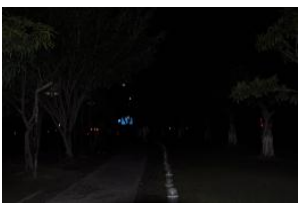

a) Orijinal
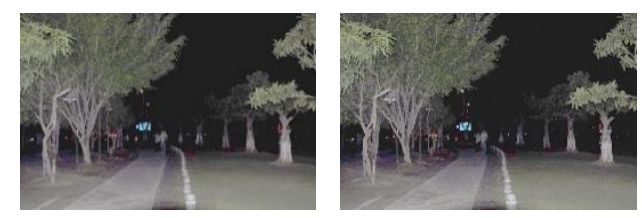
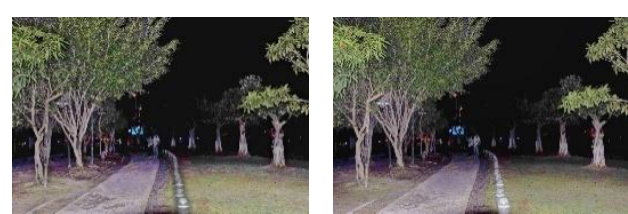
b) SSR

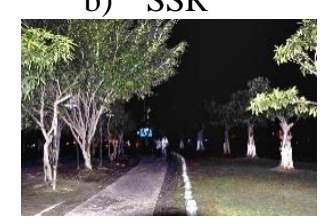

g) LIME c) MSR

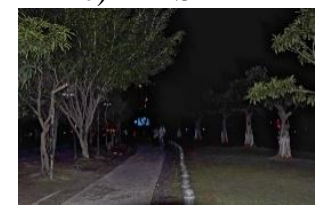

h) JieP d) MSRCR

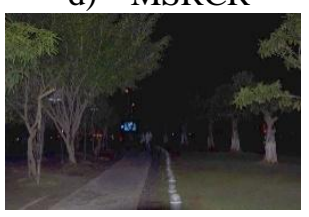

i) RRM e) NPE

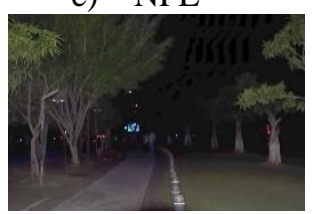

j) LR3M f) $\mathrm{MF}$

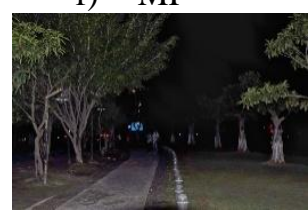

k) STAR

Şekil 4. Çalışmada kullanılan 4 numaralı düşük 1şıklı görüntünün iyileştirme sonuçları.

\section{2. İyileştirilmiş Görüntülerin Objektif Değerlendirilmesi}

Bir görüntünün görsel kalitesinin iyileştirilmesi, kişiden kişiye farklılık göstereceği için öznel bir meseledir. Ayrıca, renkli görüntü iyileştirme çalışmalarının değerlendirilmesinde evrensel olarak kabul görmüş herhangi bir kriterin bulunmaması değerlendirme işini zorlaştırmaktadır. Retineks esaslı yöntemlerin iyileştirme sonuçlarını sayısal olarak değerlendirmek için kullanılan performans ölçütleri LOE, GMSD, NIQE, ARISM ve BTMQI olarak alınmıştır.

Tablo 1. Çalışmada kullanılan yöntemlerin karşılaştırma metrik sonuçları

\begin{tabular}{|c|c|c|c|c|c|c|c|c|c|c|c|}
\hline \multirow{2}{*}{ 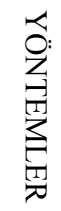 } & \multirow{2}{*}{ 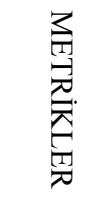 } & \multicolumn{10}{|c|}{ ÇALIŞMADA KULLANILAN GÖRÜNTÜLER } \\
\hline & & $\begin{array}{c}1 . \\
\text { Görüntü }\end{array}$ & $\begin{array}{c}2 . \\
\text { Görüntü }\end{array}$ & $\begin{array}{c}3 . \\
\text { Görüntü }\end{array}$ & $\begin{array}{c}4 . \\
\text { Görüntü }\end{array}$ & $\begin{array}{c}5 . \\
\text { Görüntü }\end{array}$ & $\begin{array}{c}6 . \\
\text { Görüntü }\end{array}$ & $\begin{array}{c}7 . \\
\text { Görüntü }\end{array}$ & $\begin{array}{c}8 . \\
\text { Görüntü }\end{array}$ & $\begin{array}{c}9 . \\
\text { Görüntü }\end{array}$ & $\begin{array}{c}10 . \\
\text { Görüntü }\end{array}$ \\
\hline \multirow{5}{*}{$\stackrel{\mathscr{D}}{\widetilde{D}}$} & LOE & 43,7204 & 57,6785 & 163,3708 & 175,167 & 95,0152 & 88,3655 & 107,9324 & 94,5203 & 168,0243 & 118,2645 \\
\hline & GMSD & 0,1306 & 0,2254 & 0,1833 & 0,2369 & 0,1008 & 0,1123 & 0,1756 & 0,2690 & 0,1904 & 0,2524 \\
\hline & NIQE & 2,9785 & 2,6048 & 2,3855 & 2,3687 & 2,1401 & 2,6384 & 4,3549 & 2,0690 & 4,4448 & 2,4994 \\
\hline & ARISM & 3,7401 & 3,2563 & 2,8236 & 2,9467 & 3,2318 & 2,7585 & 2,8010 & 3,2233 & 3,7364 & 3,2576 \\
\hline & BTMQI & 4,3177 & 3,5527 & 5,5739 & 7,8693 & 5,0889 & 6,5572 & 4,4546 & 4,3589 & 5,6702 & 3,2832 \\
\hline \multirow{5}{*}{$\frac{3}{\pi}$} & LOE & 43,6774 & 57,4991 & 164,5292 & 175,183 & 94,4713 & 87,9674 & 108,1744 & 94,5710 & 170,7793 & 118,6306 \\
\hline & GMSD & 0,1306 & 0,2246 & 0,1833 & 0,2361 & 0,1007 & 0,1123 & 0,1754 & 0,2690 & 0,1900 & 0,2524 \\
\hline & NIQE & 3,0119 & 2,6584 & 2,4023 & 2,3632 & 2,1396 & 2,6803 & 4,0996 & 2,0470 & 4,1669 & 2,6199 \\
\hline & ARISM & 3,8266 & 3,2553 & 2,8326 & 2,9944 & 3,2907 & 2,7623 & 2,8068 & 3,2309 & 3,8685 & 3,2591 \\
\hline & BTMQI & 4,2121 & 3,5091 & 5,4541 & 7,7976 & 5,0237 & 6,5455 & 4,2099 & 4,3679 & 5,5562 & 0764 \\
\hline \multirow{5}{*}{$\begin{array}{l}3 \\
\widetilde{\pi} \\
\Omega\end{array}$} & LOE & 101,857 & 155,545 & 194,0563 & 191,849 & 161,289 & 266,829 & 119,5484 & 174,653 & 199,5736 & 131,4367 \\
\hline & GMSD & 0,1249 & 0,2145 & 0,1795 & 0,2224 & 0,0990 & 0,1119 & 0,1779 & 0,1562 & 0,1698 & 0,2410 \\
\hline & NIQE & 2,6380 & 2,5071 & 2,4081 & 2,3582 & 2,1708 & 2,6822 & 4,2008 & 2,9254 & 4,0434 & 2,6197 \\
\hline & ARISM & 3,5969 & 3,1811 & 2,8214 & 2,9443 & 3,2121 & 2,7696 & 2,8830 & 3,1147 & 3,3951 & 3,2355 \\
\hline & BTMQI & 4,1645 & 2,7163 & 5,0237 & 8,1190 & 4,9983 & 6,4720 & 4,8537 & 4,5637 & 6,0737 & 3,0686 \\
\hline \multirow{5}{*}{ 㓂 } & LOE & 670,107 & 324,175 & 398,621 & 395,385 & 486,591 & 293,348 & 785,067 & 536,513 & 384,9732 & 353,9524 \\
\hline & GMSD & 0,1016 & 0,1359 & 0,1906 & 0,2899 & 0,1051 & 0,1297 & 0,1571 & 0,2188 & 0,1744 & 0,2369 \\
\hline & NIQE & 2,5648 & 2,1633 & 2,2157 & 3,0633 & 2,1262 & 2,5165 & 3,8678 & 2,3235 & 4,7332 & 3,0556 \\
\hline & ARISM & 3,8282 & 3,0430 & 2,8569 & 3,1242 & 3,2572 & 2,8593 & 2,9240 & 3,1776 & 3,5634 & 3,1028 \\
\hline & BTMQI & 4,0669 & 3,0384 & 2,4442 & 6,8320 & 2,3564 & 5,1854 & 3,6683 & 3,3614 & 6,6290 & 3,2942 \\
\hline \multirow{5}{*}{ 光 } & LOE & 127,700 & 172,436 & 235,201 & 235,145 & 223,459 & 480,985 & 167,527 & 223,511 & 190,466 & 135,651 \\
\hline & GMSD & 0,0853 & 0,1337 & & 0,2761 & 0,1081 & 0,1200 & 0,1500 & 0,1955 & 0,1605 & 0,1866 \\
\hline & NIQE & 2,8638 & 2,4694 & 2,3257 & 4,0008 & 2,1105 & 2,8287 & 3,8372 & 3,1153 & 4,5678 & 3,1231 \\
\hline & ARISM & 3,4514 & 2,9503 & 2,7953 & 3,0606 & 3,0980 & 2,8184 & 2,8690 & 3,0609 & 3,4643 & 3,0720 \\
\hline & BTMQI & 3,4313 & 2,8661 & 2,5207 & 6,2685 & 2,0156 & 3,6138 & 4,3215 & 3,2343 & 5,9690 & 3,2103 \\
\hline \multirow{5}{*}{ 家 } & LOE & 285,823 & 373,186 & 394,100 & 285,488 & 340,417 & 469,406 & 299,477 & 312,438 & 336,941 & 274,714 \\
\hline & GMSD & 0,0001 & 0,00025 & 0,00021 & 0,0004 & 0,00014 & 0,00013 & 0,00017 & 0,00029 & 0,00022 & 0,00024 \\
\hline & NIQE & 2,6785 & 2,5317 & 2,4018 & 3,1056 & 2,1552 & 2,8020 & 5,0058 & 2,7009 & 4,7003 & 3,0382 \\
\hline & ARISM & 1,3596 & 1,9918 & 2,0744 & 2,2911 & 2,2501 & 1,3070 & 1,9344 & 2,1526 & 1,9971 & 2,1794 \\
\hline & BTMQI & 4,3133 & 3,7995 & 5,4414 & 4,8205 & 4,6413 & 4,6935 & 5,4082 & 3,6501 & 5,2515 & 4,3814 \\
\hline \multirow{5}{*}{$\vec{\nabla}$} & LOE & 153,354 & 150,903 & 205,536 & 306,688 & 238,573 & 129,022 & 257,388 & 231,884 & 447,950 & 149,044 \\
\hline & GMSD & 0,00001 & 0,00002 & 0,00004 & 0,00004 & 0,00002 & 0,00002 & 0,00003 & 0,00005 & 0,00002 & 0,00003 \\
\hline & NIQE & 2,5825 & 2,2692 & 2,5569 & 2,3636 & 1,9142 & 3,0581 & 3,7186 & 2,5225 & 3,5079 & 2,4156 \\
\hline & ARISM & 1,1640 & 1,1276 & 1,1719 & 1,2250 & 1,1843 & 1,1448 & 1,0694 & 1,1272 & 1,1715 & 1,0376 \\
\hline & BTMQI & 5,1641 & 5,6786 & 3,2213 & 6,4519 & 3,5449 & 4,6739 & 4,8869 & 5,6843 & 6,6887 & 6,2655 \\
\hline \multirow{5}{*}{ 軍 } & LOE & 32,0083 & 33,3543 & 94,7545 & 203,086 & 55,0319 & 51,0529 & 51,7860 & 67,2146 & 235,258 & 84,6309 \\
\hline & GMSD & 0,3272 & 0,2741 & 0,3310 & 0,1744 & 0,3016 & 0,2447 & 0,2803 & 0,2932 & 0,2138 & 0,1960 \\
\hline & NIQE & 2,7923 & 2,2544 & 2,2877 & 2,2847 & 2,2992 & 2,6224 & 4,2954 & 2,1826 & 4,2807 & 2,9407 \\
\hline & ARISM & 1,1540 & 1,1200 & 1,1594 & 0,9623 & 1,1781 & 1,1072 & 1,0466 & 1,1007 & 1,1657 & 1,0055 \\
\hline & BTMQI & 4,0787 & 3,0218 & 4,3144 & 6,3678 & 3,7521 & 5,2415 & 6,4990 & 3,7017 & 5,9973 & 4,1662 \\
\hline \multirow{5}{*}{ 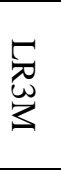 } & LOE & 127,071 & 190,902 & 195,853 & 185,88 & 198,654 & 174,635 & 126,101 & 260,426 & 235,915 & 134,368 \\
\hline & GMSD & 0,00008 & 0,00005 & 0,00003 & 0,00003 & 0,00005 & 0,00004 & 0,00005 & 0,00006 & 0,00005 & 0,00004 \\
\hline & NIQE & 3,9537 & 2,3729 & 3,8712 & 3,9580 & 3,9645 & 3,8542 & 4,8243 & 4,1150 & 4,5376 & 3,1461 \\
\hline & ARISM & 2,1231 & 1,8713 & 1,6524 & 1,7501 & 1,7582 & 1,9865 & 1,9239 & 1,2549 & 1,9728 & 1,9630 \\
\hline & BTMQI & 4,4693 & 3,0301 & 5,6321 & 6,8525 & 6,0258 & 4,8271 & 5,5994 & 3,8280 & 6,3026 & 4,4259 \\
\hline
\end{tabular}




\begin{tabular}{|l|l|l|l|l|l|l|l|l|l|l|l|}
\hline \multirow{3}{*}{$\approx$} & LOE & 39,3943 & 42,1504 & 95,4458 & 285,335 & 58,1961 & 54,6463 & 73,2768 & 133,785 & 168,200 & 124,640 \\
\cline { 2 - 12 } & GMSD & 0,3310 & 0,3291 & 0,3310 & 0,3376 & 0,3390 & 0,2937 & 0,3205 & 0,3555 & 0,2702 & 0,2933 \\
\cline { 2 - 12 } & NIQE & 2,5082 & 2,1731 & 2,8371 & 3,1382 & 1,8427 & 2,9548 & 4,3187 & 3,0472 & 3,7932 & 2,7368 \\
\cline { 2 - 12 } & ARISM & 3,1770 & 2,9398 & 2,7394 & 2,7317 & 2,9523 & 2,7496 & 2,7577 & 2,8444 & 3,2854 & 2,9935 \\
\cline { 2 - 12 } & BTMQI & 3,8130 & 2,7576 & 2,1127 & 6,0990 & 1,7914 & 4,5707 & 5,6612 & 3,4067 & 6,2157 & 4,3042 \\
\hline
\end{tabular}

Performans ölçütlerinin sayısal sonuçları görsel olarak Şekil 5 de ve her bir görüntüden elde edilen sayısal sonuçlar ise Tablo 1 de verilmiştir. Şekil 5 (a) da ki LOE sonuçlarına göre en iyi performans sırasıyla RRM, SSR ve MSR yöntemlerinde gerçekleşmiştir. Bu üç yönteminde yerel alanlardaki aydınlık değişiminin yüksek orandan gerçekleştiği söylenebilir. Ancak görüntünün doğallığından da uzaklaşıldığı kaçınılmaz bir sonuç olmuştur.

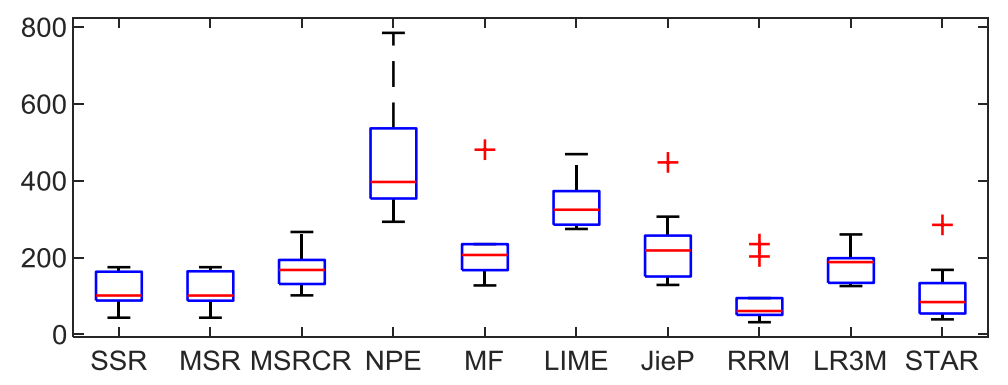

a) LOE Karşılaştırma metriği blok diyagram sonuçları

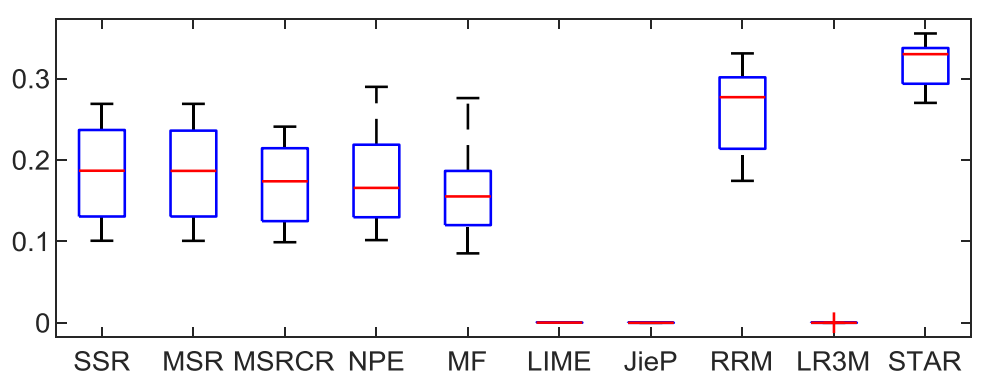

b) GMSD Karşılaştırma metriği blok diyagram sonuçları

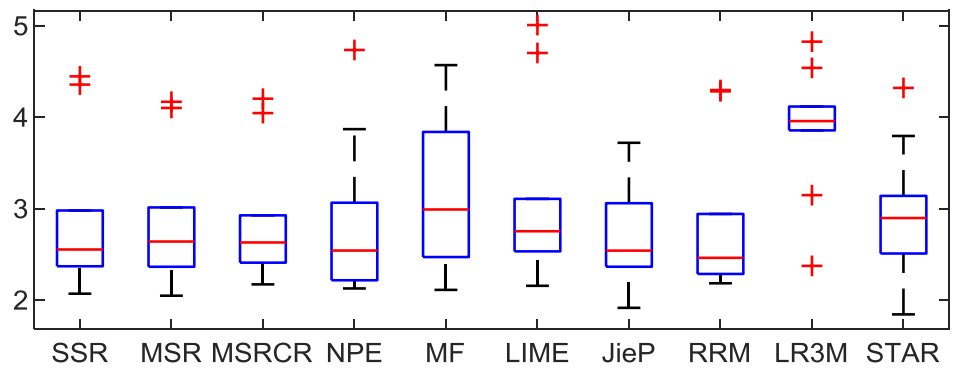

c) NIQE Karşılaştırma metriği blok diyagram sonuçları

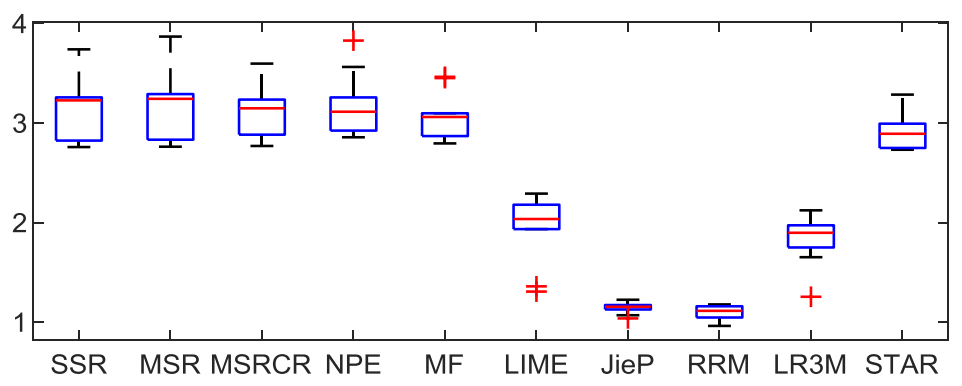

d) ARISM Karşılaştırma metriği blok diyagram sonuçları 


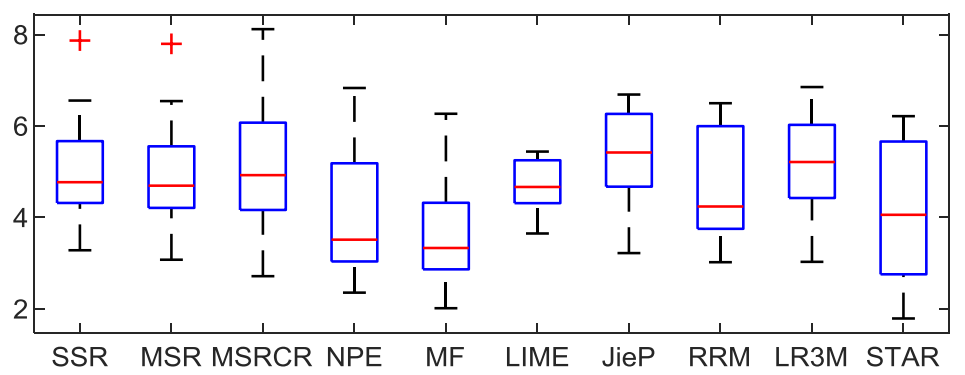

e) BTMQI Karşılaştırma metriği blok diyagram sonuçları

Şekil 5. Yöntemlerin karşılaştırma metrik sonuçlarına göre kutu grafikleri

Şekil 5 (b) de yer verilmiş olan GMSD kutu grafik sonuçlarına göre, LIME, JieP ve LR3M yöntemleri ön plana çıkmıştır. Bu üç yöntemin sübjektif değerlendirmede de iyi performans göstermesi GMSD'nin insan görsel algısına paralel davranış gösterdiği sonucu çıkartılabilir. GMSD denin ölçme esasına göre bu üç yöntemde yapısal bozukluklar en az oranda gerçekleşmiştir.

Şekil 5 (c) de yer alan NIQE metrik sonucuna göre NPE, JieP ve RRM en iyi sonuçlara sahiptir. Bu yöntemlerde görüntülerin doğal görüntü kalitesi korunmuştur.

ARISM metriğine göre, bir piksele karşıllk gelen otoregresif parametrelerinde yüksek benzerlik değerlerinin oluşması, o konumun daha zayıf keskinliğe sahip olduğu anlamına gelmektedir. Yani, ARISM görüntü keskinlik derecesinin ölçümünde tercih edilmektedir. Buna göre, LIME, JieP, RRM ve LR3M yöntemleri en iyi sonuçlara sahiptir. Ayrıca bu yöntemlerin görsel sübjektif değerlendirmelerde de ön plana çıkmaları ARISM metriğinin insan görsel algısına paralel hareket ettiği sonucuna varılabilir.

BTMQI metriği görüntüden elde edilen entropi, renklilik bilgisi ve yapısal özellikleri analiz ederek görüntü kalitesini ortaya koymaya çalışmaktadır. Şekil 5 (e) BTMQI sonuçları incelendiğinde MF, NPE ve STAR yöntemlerinde görüntünün renklilik kalitesinin arttığı sonucu çıkarılmıştır.

Tablo 2. Çalışmada kullanılan yöntemlerin işlem süresi sonuçları

\begin{tabular}{|c|c|c|c|c|c|c|c|c|c|c|c|}
\hline \multirow{2}{*}{ 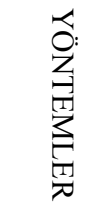 } & \multicolumn{10}{|c|}{ ÇALIŞMADA KULLANILAN GÖRÜNTÜLER } & \multirow{2}{*}{$\begin{array}{l}0 \\
\stackrel{0}{9} \\
2 \\
2 \\
2\end{array}$} \\
\hline & $\begin{array}{c}1 . \\
\text { Görüntü }\end{array}$ & $\begin{array}{c}2 . \\
\text { Görüntü }\end{array}$ & $\begin{array}{c}3 . \\
\text { Görüntü }\end{array}$ & $\begin{array}{c}4 . \\
\text { Görüntü }\end{array}$ & $\begin{array}{c}5 . \\
\text { Görüntü }\end{array}$ & $\begin{array}{c}6 . \\
\text { Görüntü }\end{array}$ & $\begin{array}{c}7 . \\
\text { Görüntü }\end{array}$ & $\begin{array}{c}8 . \\
\text { Görüntü }\end{array}$ & $\begin{array}{c}9 . \\
\text { Görüntü }\end{array}$ & $\begin{array}{c}10 . \\
\text { Görüntü }\end{array}$ & \\
\hline SSR & 0,6306 & 0,2993 & 4,1410 & 0,8505 & 3,4046 & 3,9954 & 0,2392 & 0,4469 & 0,2646 & 2,9667 & 1,7238 \\
\hline MSR & 1,0845 & 0,2897 & 4,2171 & 0,9139 & 3,6017 & 4,3019 & 0,2525 & 0,6003 & 0,2489 & 2,9436 & 1,8454 \\
\hline MSRCR & 0,7140 & 0,3118 & 4,5083 & 0,9679 & 4,0314 & 4,6122 & 0,3001 & 0,5834 & 0,2859 & 3,0425 & 1,9357 \\
\hline NPE & 20,2972 & 11,1829 & 110,710 & 30,1159 & 125,523 & 110,573 & 8,2966 & 8,1283 & 9,3050 & 36,0297 & 47,016 \\
\hline MF & 7,6544 & 0,7384 & 3,5343 & 1,0972 & 3,2920 & 3,7114 & 0,6760 & 0,6542 & 0,8123 & 1,2556 & 2,3425 \\
\hline LIME & 6,6963 & 1,0205 & 8,6514 & 2,3289 & 10,1781 & 7,8430 & 0,9549 & 0,8863 & 0,9465 & 2,8943 & 4,2400 \\
\hline JieP & 10,2553 & 4,4367 & 56,1361 & 21,0804 & 64,0177 & 43,4293 & 4,0498 & 3,7764 & 3,2989 & 15,8941 & 22,637 \\
\hline RRM & 18,8038 & 7,7666 & 78,5873 & 20,6159 & 93,7806 & 77,7047 & 7,0682 & 6,7599 & 6,3547 & 27,466 & 34,490 \\
\hline LR3M & 349,311 & 195,83 & 1645,28 & 1541,93 & 1100,61 & 223,54 & 134,98 & 147,41 & 157,61 & 1135,40 & 663,19 \\
\hline STAR & 8,2186 & 2,0174 & 23,6725 & 42,3042 & 35,0255 & 15,4468 & 1,7935 & 6,5964 & 1,3692 & 31,4942 & 16,793 \\
\hline
\end{tabular}

Retineks esaslı yöntemlerin her bir görüntü için çalışma ve ortalama süreleri Tablo 2 de verilmiştir. Tablo 2 incelendiğinde LR3M, NPE ve RRM yöntemleri işlem süresi en uzun yöntemlerdir. Görsel kalite ve metrik sonuçlara göre iyi performans göstermiş olan LIME’nin 4,24 sn gibi ortalama işlem süresine sahip olması bir başka tercih nedeni olarak görülebilir. Bunun yanında renklilik bilgisini yüksek oranda sağlayan MF'nin de 2,34 ortalamaya sahip olması ikinci avantajı olarak görülebilir.

\section{SONUÇ}

Bu çalışma, Retineks tabanlı algoritmalara dayanan görüntü iyileştirme çalışmalarının karşılaştırmalı analizini sunmaktadır. Günümüze kadar gelen ve çok tercih edilen düşük ışıklı on adet Retineks esaslı yöntem alınmış ve beş adet karşılaştırma ölçüm metrikleri performans karşılaştırması olarak kullanılmıştır.

SSR, MSR ve MSRCR yöntemlerinde görüntüler doğal değildir ve aşırı iyileşme sorunu çalışılan bütün görüntülerde sıklıkla görülmüştür. NPE ve MF yöntemlerinde kontrast artışı az oranda gerçekleşmiştir. Diğer görüntülere göre daha koyu bir görünüşe sahiptirler. RRM görüntülerinin tamamında bulanık bir yapı etken durumdadır. Bu durum ayrıntıların kaybolmasına sebep olmuştur. JieP ve STAR yöntemlerinde görüntü kontrastı geniş ve detaylar daha düzgün şekilde iyileştirme sağlanmıştır. Görüntü içerisindeki kenar ve bölge bilgilerinin daha belirgin olduğu görülmektedir. LIME ve LR3M yöntemlerinin işlevsel bir yöntem oldukları sonucuna 
varılmıştır. Çünkü keskinlik ve açıklık başarılı bir şekilde gerçekleştirilmiştir. Bunlara ilaveten LIME'nin işlem süresi ortalama 4,24sn ile uygulanabilir olduğunu göstermektedir. İlerleyen çalışmalar içerisinde karşılaştırma sonuçları referans alınarak, yöntemlerin güçlü özellikleri birleştiren yeni bir Retineks esaslı görüntü iyileştirme algoritma geliştirilmesi düşünülmektedir.

\section{Yazar Katkıları}

Yazarlar çalışmaya eşit oranlı katkı sunmuşlardır.

\section{Çıkar Çatışması}

Makale yazarları aralarında herhangi bir çıkar çatışması yoktur.

\section{KAYNAKÇA}

[1] S. M. Pizer, "Contrast-limited adaptive histogram equalization: Speed and effectiveness stephen $\mathrm{m}$. pizer, r. eugene johnston, james p. ericksen, bonnie c. yankaskas, keith e. muller medical image display research group", In Proceedings of the F, 1990.

[2] J. C. Russ, The image processing handbook. CRC press, 2016.

[3] Y. T. Kim, "Contrast enhancement using brightness preserving bi-histogram equalization", IEEE transactions on Consumer Electronics, vol. 43, no.1, pp. 1-8, 1997.

[4] Q. Wang, R. K. Ward, "Fast image/video contrast enhancement based on weighted thresholded histogram equalization", IEEE transactions on Consumer Electronics, vol. 53, no. 2, 2007.

[5] L. Li, R. Wang, W. Wang \& W. Gao, "A low-light image enhancement method for both denoising and contrast enlarging", In 2015 IEEE International Conference on Image Processing (ICIP), pp. 37303734, 2015.

[6] X. Zhang, P. Shen, L. Luo, L. Zhang \& J. Song, "Enhancement and noise reduction of very low light level images", In Proceedings of the 21 st International Conference on Pattern Recognition (ICPR2012), IEEE, pp. 2034-2037, 2012.

[7] Z. Huang, T. Zhang, Q. Li \& H. Fang, "Adaptive gamma correction based on cumulative histogram for enhancing near-infrared images", Infrared Physics \& Technology, vol. 79, pp. 205-215, 2016.

[8] S. C. Huang, F. C. Cheng \& Y. S. Chiu, "Efficient contrast enhancement using adaptive gamma correction with weighting distribution", IEEE transactions on image processing, vol. 22, no. 3, pp. 1032-1041, 2012.

[9] G. Deng, "A generalized gamma correction algorithm based on the SLIP model", EURASIP Journal on Advances in Signal Processing, 2016(1), 69, 2016.

[10] D. J. Jobson, Z. U. Rahman \& G. A. Woodell, "Properties and performance of a center/surround retinex", IEEE transactions on image processing, vol. 6, no. 3, pp. 451-462, 1997.

[11] Z. U. Rahman, D. J. Jobson \& G. A. Woodell, "Multi-scale retinex for color image enhancement", In Proceedings of 3rd IEEE International Conference on Image Processing, vol. 3, pp. 10031006, 1996.
[12] D. J. Jobson, Z. U. Rahman \& G. A. Woodell, "A multiscale retinex for bridging the gap between color images and the human observation of scenes", IEEE Transactions on Image processing, vol. 6, no. 7, pp. 965-976, 1997.

[13] M. K. Ng, W. Wang, "A total variation model for Retinex", SIAM Journal on Imaging Sciences, vol. 4, no. 1, pp. 345-365, 2011.

[14] S. Wang, J. Zheng, H. M. Hu, \& B. Li, "Naturalness preserved enhancement algorithm for non-uniform illumination images", IEEE Transactions on Image Processing, vol. 22, no. 9, pp. 3538-3548, 2013.

[15] X. Fu, Y. Liao, D. Zeng, Y. Huang, X. P. Zhang \& $X$. Ding, "A probabilistic method for image enhancement with simultaneous illumination and reflectance estimation", IEEE Transactions on Image Processing, vol. 24, no. 12, pp. 4965-4977, 2015 .

[16] X. Fu, D. Zeng, Y. Huang, Y. Liao, X. Ding \& J. Paisley, "A fusion-based enhancing method for weakly illuminated images", Signal Processing, vol. 129, pp. 82-96, 2016.

[17] X. Guo, Y. Li, \& H. Ling, "LIME: Low-light image enhancement via illumination map estimation", IEEE Transactions on image processing, vol. 26, no. 2, pp. 982-993, 2016.

[18] B. Cai, X. Xu, K. Guo, K. Jia, B. Hu \& D. Tao, "A joint intrinsic-extrinsic prior model for retinex", In Proceedings of the IEEE international conference on computer vision, pp. 4000-4009, 2017.

[19] M. Li, J. Liu, W. Yang, X. Sun \& Z. Guo, "Structure-revealing low-light image enhancement via robust retinex model", IEEE Transactions on Image Processing, vol. 27, no. 6, pp. 2828-2841, 2018.

[20] X. Ren, W. Yang, W. H. Cheng \& J. Liu, "LR3M: robust low-light enhancement via low-rank regularized retinex model", IEEE Transactions on Image Processing, vol. 29, pp. 5862-5876, 2020.

[21] J. Xu, Y. Hou, D. Ren, L. Liu, F. Zhu, M. Yu \& L. Shao, "STAR: A structure and texture aware retinex model", IEEE Transactions on Image Processing, vol. 29, pp. 5022-5037, 2020.

[22] E. H. Land, J. J. McCann, "Li1ghtness and retinex theory", Josa, vol. 61, no. 1, pp. 1-11, 1971.

[23] E. H. Land, "An alternative technique for the computation of the designator in the retinex theory 
of color vision", Proceedings of the national academy of sciences, vol. 83, no. 10, pp. 3078-3080, 1986.

[24] W. Xue, L. Zhang, X. Mou \& A. C. Bovik, "Gradient magnitude similarity deviation: A highly efficient perceptual image quality index", IEEE Transactions on Image Processing, vol. 23, no. 2, pp. 684-695, 2013.

[25] A. Mittal, R. Soundararajan \& A. C. Bovik, "Making a "completely blind" image quality analyzer", IEEE Signal processing letters, vol. 20, no. 3, pp. 209-212, 2012.
[26] K. Gu, G. Zhai, W. Lin, X. Yang \& W. Zhang, "Noreference image sharpness assessment in autoregressive parameter space", IEEE Transactions on Image Processing, vol. 24, no. 10, pp. 3218-3231, 2015.

[27] K. Gu, S. Wang, G. Zhai, S. Ma, X. Yang, W. Lin \& W. Gao, "Blind quality assessment of tone-mapped images via analysis of information, naturalness, and structure", IEEE Transactions on Multimedia, vol. 18, no. 3,pp. 432-443, 2016. 